\title{
The Weather Research and Forecasting Model with Aerosol-Cloud Interactions (WRF-ACI): Development, Evaluation, and Initial Application ${ }^{\mathscr{O}}$
}

\author{
Timothy Glotfelty, Kiran Alapaty, and Jian He \\ National Exposure Research Laboratory, U.S. Environmental Protection Agency, Research Triangle Park, North Carolina \\ PATRICK HAWBECKER \\ Department of Marine, Earth, and Atmospheric Sciences, North Carolina State University, Raleigh, North Carolina \\ XiAOLIANG SONG AND GuANG Zhang \\ Scripps Institution of Oceanography, University of California, San Diego, La Jolla, California
}

(Manuscript received 3 August 2018, in final form 28 January 2019)

\begin{abstract}
The Weather Research and Forecasting Model with Aerosol-Cloud Interactions (WRF-ACI) is developed for studying aerosol effects on gridscale and subgrid-scale clouds using common aerosol activation and ice nucleation formulations and double-moment cloud microphysics in a scale-aware subgrid-scale parameterization scheme. Comparisons of both the standard WRF and WRF-ACI models' results for a summer season against satellite and reanalysis estimates show that the WRF-ACI system improves the simulation of cloud liquid and ice water paths. Correlation coefficients for nearly all evaluated parameters are improved, while other variables show slight degradation. Results indicate a strong cloud lifetime effect from current climatological aerosols increasing domain average cloud liquid water path and reducing domain average precipitation as compared to a simulation with aerosols reduced by $90 \%$. Increased cloud-top heights indicate a thermodynamic invigoration effect, but the impact of thermodynamic invigoration on precipitation is overwhelmed by the cloud lifetime effect. A combination of cloud lifetime and cloud albedo effects increases domain average shortwave cloud forcing by $\sim 3.0 \mathrm{~W} \mathrm{~m}^{-2}$. Subgrid-scale clouds experience a stronger response to aerosol levels, while gridscale clouds are subject to thermodynamic feedbacks because of the design of the WRF modeling framework. The magnitude of aerosol indirect effects is shown to be sensitive to the choice of autoconversion parameterization used in both the gridscale and subgrid-scale cloud microphysics, but spatial patterns remain qualitatively similar. These results indicate that the WRF-ACI model provides the community with a computationally efficient tool for exploring aerosol-cloud interactions.
\end{abstract}

\section{Introduction}

Aerosols have various impacts on clouds by acting as either cloud condensation nuclei or ice nuclei and these collections of effects on radiation and precipitation, known as aerosol indirect effects (AIE), have been documented by the Intergovernmental Panel on Climate Change in multiple reports (e.g., Lohmann and Feichter 2005; Denman et al. 2007; Tao et al. 2012; Boucher et al.

Supplemental information related to this paper is available at the Journals Online website: https://doi.org/10.1175/MWR-D-180267.s1.

Corresponding author: alapaty.kiran@epa.gov
2013). The first AIE, also known as the "cloud albedo effect" or "Twomey effect," describes how increases in cloud droplet number concentration (CDNC) from increasing aerosol levels subsequently lead to an increase in cloud albedo assuming cloud water remains constant (e.g., Twomey 1977). The second AIE, or the "cloud lifetime effect," describes how reduced precipitation from higher CDNC leads to increases in cloud water and cloud coverage by extending the lifetime of precipitating clouds (e.g., Albrecht 1989). The glaciation effect describes the process where aerosols can act as contact ice nuclei thereby enhancing precipitation in mixed-phase clouds by enhancing the rate of the Bergeron-Findeisen process (e.g., Lohmann 2002). The enhancement of cloud water from the cloud life effect can also allow for 
greater lofting and freezing of cloud droplets which release latent heat that invigorates the updrafts and precipitation via the thermodynamic invigoration effect (e.g., Rosenfeld et al. 2008). AIEs are an open field of study with many discoveries of new effects (e.g., Lohmann and Feichter 2005; Tao et al. 2012; Kudzotsa et al. 2016a,b). However, despite ongoing research, aerosol-cloud interactions (ACI) remain a large source of debate and uncertainty in the scientific community (e.g., Denman et al. 2007; Bender 2012; Boucher et al. 2013; Zelinka et al. 2014).

The Weather Research and Forecasting (WRF) Model is a state of the art numerical weather prediction model capable of supporting high-resolution simulations (Skamarock and Klemp 2008). The version of WRF (3.8.1) available to the weather modeling community is limited in terms of ACI, since none of the current subgrid-scale cumulus parameterizations contain cloud microphysical processes and many of the gridscale cloud microphysics parameterizations use simplified spatially and temporally uniform assumptions for CDNC. There are "aerosol aware" gridscale microphysics and cumulus parameterization options available in WRF (e.g., Grell and Freitas 2014, hereafter GF14; Thompson and Eidhammer 2014, hereafter TE14). However, to the authors' knowledge, these schemes do not treat the speciation effects of aerosols and are not harmonized together into a comprehensive self-consistent system to simulate ACI across all scales for both convective and nonconvective environments.

The above limitations can be somewhat offset using the highly specialized Weather Research and Forecasting Model with Chemistry (WRF-Chem; Grell et al. 2005) or Weather Research and Forecasting Model with CAM5 physics suite (WRF-CAM5; Ma et al. 2014; Lim et al. 2014) configurations. Both the WRF-Chem and WRF-CAM5 configurations of WRF have prognostic simulations of aerosols, which is beneficial for simulating ACI, but come with the additional limitation of large computational expense and a laborious preparation of several other input data. For example, using either the simplistic or sophisticated gas and aerosol mechanisms in WRF-Chem necessary to accurately predict ambient aerosol conditions can increase simulation times by anywhere from $116 \%$ to $2000 \%$ compared to simplistic WRF-Chem simulations of only dust tracers (https:// ruc.noaa.gov/wrf/wrf-chem/wrf_tutorial_2018/cost.pdf). Additionally, the WRF-CAM5 configuration has some limitations representing ACI since the Morrison and Gettelman (2008) microphysics parameterization uses a diagnostic rain scheme that artificially enhances rain sensitivity to aerosols (Posselt and Lohmann 2009; Ma et al. 2014). The Zhang and McFarlane (1995) cumulus parameterization that is part of WRF-CAM5 may also be somewhat limited since it is designed for use in general circulation models and lacks scale awareness, even though the WRF-CAM5 package has been shown to have comparable performance to WRF-Chem (Ma et al. 2014). Further, WRF-CAM5's usage of different types of aerosols with different activation schemes in gridscale and subgrid-scale formulations may constitute some inconsistency and add to increasing uncertainty.

To help with alleviating the above described limitations with WRF and without invoking integrated modeling complexities, in this work we present a methodology to include AIE with a consistent treatment of aerosol activation and ice nucleation physics for resolved and parameterized clouds using a bias corrected prescribed aerosol climatology. To that effect, temporally and spatially varying ACI are introduced into the WRF Model. Specific objectives of this study are to 1) evaluate the performance of the WRF Model with the new ACI treatments, 2) compare its performance with the base WRF Model, 3) investigate the impact of current climatological aerosols on high-resolution regional seasonal applications, and 4) investigate the uncertainty of ACI introduced by the cloud drop to rain drop autoconversion parameterizations over the eastern United States.

\section{Model development}

In this section, we describe modifications we have made to the subgrid-scale and gridscale cloud formulations and radiation scheme along with the preparation and refinements of aerosol inputs used in our study.

\section{a. Subgrid-scale aerosol-cloud interactions}

To overcome some of the above limitations of the WRF 3.8.1 model, the subgrid-scale convective cloud microphysics parameterization of Song and Zhang (2011, hereafter SZ11) has been modified and incorporated into the multiscale Kain-Fritsch cumulus parameterization (MSKF; Alapaty et al. 2014; Mahoney 2016; Zheng et al. 2016). The MSKF cumulus parameterization, which was based on the original Kain-Fritsch cumulus parameterization (Kain and Fritsch 1990; 1993; Kain 2004), has scale-dependent formulations and several other improvements to facilitate the simulation of AIEs. These include 1) shallow and deep cloud radiation interactions, 2) a scale-dependent generalized dynamic convective adjustment time scale for shallow and deep convective clouds, 3) scale-dependent and lifting condensation level-based lateral entrainment, 4) scale-dependent fallout rate for condensates, 5) scale-dependent atmospheric stabilization capacity, and 6) elimination of double counting of precipitation for saturated atmospheric conditions. For further details about the MSKF scheme, 
readers are referred to Text $\mathrm{S} 1$ in the online supplemental material. The SZ11 microphysics scheme is a bulk two moment microphysics package that simulates the mass and number of four hydrometeor classes including cloud liquid water, cloud ice, snow, and rain. The SZ11 scheme simulates several key microphysical processes including autoconversion, accretion, collection, cloud droplet activation, freezing, the BergeronFindeisen process (Wegener 1911; Bergeron 1935; Findeisen 1938), ice nucleation, and convective detrainment of hydrometeors (SZ11). For further details, see the Text S2 in the supplemental material.

Additionally, a few scientific updates were added to the MSKF scheme and the embedded SZ11 microphysics. The cloud droplet to rain autoconversion scheme in SZ11 is based on the formulation of Khairoutdinov and Kogan (2000), which may be inadequate for deep convection since it was generated by fitting empirical data for marine stratocumulus clouds. This formulation is updated using the constants from Kogan (2013) that are derived for cumulus clouds. The ice and liquid water fractions within the MSKF scheme were originally determined by a default profile from the Kain-Fritsch scheme. This profile has been updated using remote sensing measurements from the Moderate Resolution Imaging Spectroradiometer (MODIS) and Cloud-Aerosol Lidar and Infrared Pathfinder Satellite Observations (CALIPSO) datasets to better represent the formation of supercooled liquid water based on $\mathrm{Hu}$ et al. (2010). The fraction of supercooled water in clouds is a function of cloud temperature $T_{c}\left({ }^{\circ} \mathrm{C}\right)$ following the sigmoid function $f\left(T_{c}\right)$,

$$
f\left(T_{c}\right)=\frac{1}{1+e^{-p\left(T_{c}\right)}}
$$

where $p\left(T_{c}\right)$ is

$$
\begin{aligned}
p\left(T_{c}\right)= & 7.6725+1.0118 T_{c}+0.1422 T_{c}^{2}+0.0106 T_{c}^{3} \\
& +3.39 \times 10^{-4} T_{c}^{4}+3.95 \times 10^{-6} T_{c}^{5}
\end{aligned}
$$

and describes the polynomial fit between $T_{c}$ and $f\left(T_{c}\right)$ (Hu et al. 2010).

Although the SZ11 microphysics package is part of a version of WRF-CAM5 (Lim et al. 2014), the incorporation of SZ11 into the MSKF parameterization is an important advancement enabling the study of ACI in the so-called "gray zone" or convection-permitting scales (e.g., from 12- to 1-km grid spacing). The use of cumulus parameterizations in the gray zone is still a matter of debate but the consensus in the community is that a cumulus parameterization should "shut itself off" at finer resolutions and become more active at coarser resolutions (Hong and Dudhia 2012). The MSKF parameterization's scale aware aspects fulfill this requirement and also allow for the simulation of convective cloud-radiation feedbacks necessary to simulate the aerosol indirect effects (Alapaty et al. 2012; Zheng et al. 2016).

\section{b. Gridscale aerosol-cloud interactions}

To simulate ACI across scales, a consistent treatment for ACI is needed in both the gridscale and subgrid-scale cloud microphysics. To accomplish this aspect, the aerosol activation and ice nucleation components of the SZ11 microphysics package have been implemented into the Morrison double-moment microphysics (MDM) parameterization (Morrison et al. 2005, 2009) within WRF. Aerosol activation within the SZ11 microphysics package is based on the method of AbdulRazzak and Ghan (2000, hereafter AG00). This scheme simulates the activation of multiple types of aerosols that compete to form cloud droplets based on their individual properties such as aerosol size and hygroscopicity. The nucleation of new cloud droplets is parameterized as a function of updraft velocity, aerosol number concentration, aerosol size distribution, and temperature. For the gridscale aerosol activation scheme a subgrid vertical velocity component is added to the gridscale vertical velocity to represent subgrid-scale variability. This subgrid-scale vertical velocity is parameterized following Eq. (24) in Morrison et al. (2005), with a mixing length scale of $20 \mathrm{~m}$. The aerosol activation scheme replaces the existing prescribed cloud droplet number concentration of $250 \mathrm{~cm}^{-3}$ used in the MDM scheme.

The second component of the gridscale ACI treatment is the ice nucleation scheme of Liu and Penner (2005, hereafter LP05). This ice nucleation scheme treats the formation of ice crystals via a combination of homogenous ice nucleation, heterogeneous immersion nucleation, and deposition/condensation ice nucleation (LP05; Liu et al. 2007). The combination of ice crystal nucleation from these three pathways replaces the Cooper (1986) ice nucleation parameterization used in the MDM scheme. More details on this ice nucleation parameterization can be found in the supplemental material. In addition to changing the ice nucleation parameterization, the threshold radius for converting ice crystals to snow $\left(D_{\mathrm{cs}}\right)$ is increased from $125 \mu \mathrm{m}$ in the default MDM scheme to $350 \mu \mathrm{m}$ in the Weather Research and Forecasting Model with Aerosol-Cloud Interactions (WRF-ACI) treatment (to achieve optimal radiation performance). Parameter $D_{\mathrm{cs}}$ is a somewhat unphysical parameter but its value exists in the range of approximately 90-400 $\mu \mathrm{m}$ (H. Morrison, NCAR, 2017, personal communication), thus this increase is justified. 


\section{c. Coupling of radiation and microphysics}

To simulate the impact of ACI on radiation, the cloud water, cloud ice, and snow mixing ratios, as well as, the cloud droplet, ice crystal, and snow effective radii from both the MSKF and the MDM schemes must be coupled to the Rapid Radiative Transfer Model for GCMs (RRTMG) longwave and shortwave radiation schemes (Clough et al. 2005; Iacono et al. 2008). In the default model, hydrometeor mixing ratios for all classes except subgrid-scale snow are already coupled to RRTMG. Therefore, the only updates to the radiation code include passing the subgrid-scale snow mixing ratios and all hydrometeor effective radii to the RRTMG scheme. The method for coupling of effective radii is the same method as described in Thompson et al. (2016), where effective radii calculated by the microphysics schemes are used instead of lookup table values for physical consistency.

\section{d. Aerosol concentrations}

The aerosol concentrations used in the new WRF-ACI treatment are generated by a version of the Community Earth System Model (Hurrell et al. 2013) developed at the North Carolina State University (CESM-NCSU; He and Zhang 2014; Gantt et al. 2014; Glotfelty et al. 2017a). Aerosol mass concentrations are obtained from a $0.9^{\circ} \times$ $1.25^{\circ}$ horizontal grid spacing global scale decadal simulation spanning the years of 2001-10 using greenhouse gases emissions from the representation concentration pathway scenario with anthropogenic forcing stabilizing at $4.5 \mathrm{~W} \mathrm{~m}^{-2}$ (RCP4.5) by 2100 (Glotfelty et al. 2017b). The aerosol concentrations from this decadal simulation are averaged into a monthly aerosol climatology, and the aerosol species from CESM-NCSU are mapped into 11 bulk aerosol species used in the SZ11 microphysics package according to Table S1 in the supplemental material. The aerosol climatology is read into the WRF Model where it is horizontally and vertically interpolated to the WRF coordinates. Aerosol concentrations are linearly interpolated between each month to correspond to the date of the WRF simulation. We have bias corrected the climatological aerosol concentrations for WRF by multiplying the CESM aerosol concentrations by the normalized mean bias values reported in Glotfelty et al. (2017b).

\section{e. Comparison to existing "aerosol aware" schemes}

As discussed in section 1, the WRF-ACI system implementation performs a similar function as the existing GF14 cumulus parameterization and TE14 gridscale cloud microphysics parameterization in WRF. In terms of cumulus parameterizations both MSKF and GF14 are aerosol and scale aware. The primary difference is that the MSKF scheme in the WRF-ACI system has subgridscale convective cloud microphysics and therefore explicit ACIs are included. The MDM scheme in WRF-ACI and the TE14 scheme both represent the impacts of spatially and temporally variable aerosols on gridscale clouds. The way in which aerosols interact with clouds are qualitatively similar, with slight differences. In the WRF-ACI MDM scheme, aerosol activation and ice nucleation are calculated using the AG00 and LP05 parameterizations mentioned above. In TE14 aerosol activation is calculated using a lookup table methodology, using similar input parameters as the AG00 scheme. Ice nucleation in TE14 is based solely on dust concentrations as opposed to sulfate, black carbon, and dust in WRF-ACI. In TE14 the dust impacts ice nucleation though the DeMott et al. (2010) parameterization for condensation and immersion freezing and the Phillips et al. (2008) parameterization for deposition nucleation. Dust concentrations are also allowed to impact the effective temperature for the freezing of water droplets. The aerosol climatology between WRF-ACI and TE14 is also different. The TE14 aerosols are based on a 2001-07 global model climatology (Colarco et al. 2010), where all hydrophilic aerosols are lumped into a single water friendly $\mathrm{CCN}$ concentration and accumulated dust mass larger than $0.5 \mu \mathrm{m}$ becomes potential ice nuclei. The TE14 scheme also allows for the advection of these species through the implementation of a simplified emissions and removal parameterization. In WRF-ACI the aerosol climatology contains additional aerosol species such as ammonium, nitrate, and secondary organic aerosol that are not treated or simplified in the TE14 climatology and the hygroscopic properties of the individual aerosol species are accounted for. However, in WRF-ACI aerosol concentrations are prescribed and thus not advected, emitted, or removed (as these processes were already performed by the host model, CESM). The main advantage of WRF-ACI over the GF14 and TE14 parameterizations is that the ACI treatment is consistent in both the gridscale and subgrid-scale clouds, allowing for the study of ACI across all model resolutions in a consistent fashion.

\section{Experimental design}

In this section, we present details of the model configuration, numerical simulations performed, and various observational datasets used in this study. A list of all acronyms used in this manuscript is provided in Table 1.

\section{a. Model configurations}

The WRF4.0 physics options that are part of the WRF-ACI treatment are listed in Table 2. These physics 
options are based on several commonly used physics configurations within the WRF and air quality community (e.g., Campbell et al. 2015). All WRF simulations are initialized with the $12-\mathrm{km}$ reanalysis of the National Centers for Environmental Prediction North American Mesoscale Forecast System (NAM) model merged with additional observations. The additional observations include upper-air radiosonde measurements, wind profiler measurements, and Weather Surveillance Radar-1988 Doppler (WSR-88D) velocity-azimuth display algorithm wind data obtained from the National Center for Atmospheric Research (NCAR) and surface meteorological fields obtained from the Meteorological Assimilation Data Ingest System. These observations are merged with the 12-km NAM reanalysis using NCAR's OBSGRID utility to generate initial conditions, boundary conditions, and nudging files for all WRF simulations.

The WRF-ACI system and the baseline simulations presented in this work use analysis nudging to reduce secondary feedbacks, especially when aerosol concentrations are perturbed, to elucidate just the impact of the aerosol indirect effects. The simulations are nudged in the free atmosphere via four-dimensional data assimilation (FDDA; Stauffer and Seaman 1990; Stauffer and Seaman 1994) and at the surface using the flux-adjusting surface data assimilation system (FASDAS; Alapaty et al. 2008; He et al. 2017). FASDAS is an analysis nudging system similar to FDDA that corrects errors in surface temperature and moisture fields in a thermodynamically consistent manner. FASDAS consists of direct nudging of temperature and water vapor mixing ratio in the lowest model layer that is balanced by an indirect adjustment of the surface sensible heat flux and latent heat fluxes in the land surface model (Alapaty et al. (2008). More details on FASDAS as implemented in WRF can be found in He et al. (2017). In the free atmosphere with FDDA, temperature and the horizontal wind speed components are nudged using a relaxing coefficient of $5.0 \times 10^{-5} \mathrm{~s}^{-1}$ and water vapor mixing ratio is nudged with a relaxation coefficient of $5 \times 10^{-6} \mathrm{~s}^{-1}$. These weak nudging values are used as they allow for numerical consistency of WRF's physics parameterizations, while still constraining model drift. These values were derived from sensitivity tests of the model configurations in Bullock et al. (2014). FASDAS nudges surface temperature and moisture using relaxation coefficients of $8.3 \times 10^{-4} \mathrm{~s}^{-1}$. The FASDAS coefficients are based on the time scale of large eddy turnover (i.e., $20 \mathrm{~min}$ ) within the boundary layer (Alapaty et al. 2008). No nudging is applied in planetary boundary layer.

Five seasonal simulations are conducted for the period of June-August (JJA) 2006 using 12-km grid spacing. The first simulation is the default WRF version 3.8.1 with the
TABLE 1. List of acronyms.

\begin{tabular}{|c|c|}
\hline Acronym & Expansion \\
\hline ACI & Aerosol-cloud interactions \\
\hline AG00 & Abdul-Razzak and Ghan (2000) \\
\hline AIE & Aerosol indirect effect \\
\hline ARF & Aerosol radiative forcing \\
\hline BASE & Simulation using default WRFv3.8.1 \\
\hline CDNC & Cloud droplet number concentration \\
\hline CERES_EBAF & $\begin{array}{l}\text { Clouds and the Earth's Radiant Energy } \\
\text { System_Energy Balanced and Filled }\end{array}$ \\
\hline CICDNC & $\begin{array}{l}\text { Column integrated cloud droplet number } \\
\text { concentration }\end{array}$ \\
\hline CIINC & $\begin{array}{l}\text { Column integrated ice number } \\
\text { concentration }\end{array}$ \\
\hline CLDFRA & Total cloud fraction \\
\hline CLE & Cloud lifetime effect \\
\hline $\mathrm{CP}$ & Cumulus parameterization \\
\hline DCCF & Deep convective cloud fraction \\
\hline FASDAS & Flux-adjusting surface data assimilation \\
\hline FDDA & Four-dimensional data assimilation \\
\hline GF14 & Grell and Freitas (2014) \\
\hline IWP & Cloud ice water path \\
\hline JJA & June-August \\
\hline KK0013 & $\begin{array}{l}\text { Khairoutdinov and Kogan (2000) and } \\
\text { Kogan (2013) }\end{array}$ \\
\hline LAERO & $\begin{array}{l}\text { Simulation with aerosol concentrations } \\
\text { reduced by } 90 \%\end{array}$ \\
\hline LD04 & Liu and Daum (2004) \\
\hline LP05 & Liu and Penner (2005) \\
\hline LWCF & Longwave cloud forcing \\
\hline LWP & Cloud liquid water path \\
\hline MB & Mean bias \\
\hline MDM & $\begin{array}{l}\text { Morrison double-moment microphysics } \\
\text { scheme }\end{array}$ \\
\hline MODIS & $\begin{array}{l}\text { Moderate Resolution Imaging } \\
\text { Spectroradiometer }\end{array}$ \\
\hline MSKF & Multiscale Kain-Fritsch \\
\hline NAM & $\begin{array}{l}\text { North American Mesoscale Forecast } \\
\text { System }\end{array}$ \\
\hline NCAR & $\begin{array}{l}\text { National Center for Atmospheric } \\
\text { Research }\end{array}$ \\
\hline NOAA-18 & $\begin{array}{l}\text { National Oceanic and Atmospheric } \\
\text { Administration- } 18 \text { satellite }\end{array}$ \\
\hline OLR & Outgoing longwave radiation \\
\hline PRF & Pseudo-radiative forcing \\
\hline PRISM & $\begin{array}{l}\text { Parameter-Elevation Regressions on } \\
\text { Independent Slopes Model }\end{array}$ \\
\hline$R$ & Pearson's correlation coefficient \\
\hline RMSE & Root-mean-square error \\
\hline RRTMG & $\begin{array}{l}\text { Rapid Radiative Transfer Model for } \\
\text { GCMs }\end{array}$ \\
\hline SWCF & Shortwave cloud forcing \\
\hline SWDOWN & $\begin{array}{l}\text { Downwelling shortwave radiation at } \\
\text { Earth's surface }\end{array}$ \\
\hline SZ11 & Song and Zhang (2011) microphysics \\
\hline TE14 & Thompson and Eidhammer (2014) \\
\hline WRF & $\begin{array}{l}\text { Weather Research and Forecasting } \\
\text { Model }\end{array}$ \\
\hline WRF-ACI & WRF with Aerosol-Cloud Interactions \\
\hline WRF-Chem & WRF with online coupled Chemistry \\
\hline WRF-CAM5 & WRF with CAM5 physics suite \\
\hline
\end{tabular}


TABLE 2. Model configurations.

\begin{tabular}{|c|c|}
\hline Parameter & Configuration \\
\hline Region & Eastern United States \\
\hline Horizontal grid spacing & $12 \mathrm{~km}$ \\
\hline Vertical levels & 35 \\
\hline Time period & June-August 2006 \\
\hline Physics Parameterization & Configuration \\
\hline Cumulus & $\begin{array}{c}\text { MSKF (Alapaty et al. 2014; Zheng } \\
\text { et al. 2016) }\end{array}$ \\
\hline Microphysics & MDM (Morrison et al. 2005, 2009) \\
\hline Boundary layer & Yonsei University (Hong et al. 2006) \\
\hline Surface layer & $\begin{array}{l}\text { Monin-Obukhov (Monin and } \\
\text { Obukhov 1954; Janjić 2002) }\end{array}$ \\
\hline Land surface model & $\begin{array}{c}\text { Noah (Chen and Dudhia 2001; Ek } \\
\text { et al. 2003) }\end{array}$ \\
\hline Radiation & $\begin{array}{c}\text { RRTMG (Clough et al. 2005; Iacono } \\
\text { et al. 2008) }\end{array}$ \\
\hline $\begin{array}{c}\text { Free-atmosphere data } \\
\text { assimilation }\end{array}$ & $\begin{array}{l}\text { FDDA (Stauffer and Seaman 1990, } \\
\text { 1994) }\end{array}$ \\
\hline Surface data assimilation & $\begin{array}{c}\text { FASDAS (Alapaty et al. 2008; He } \\
\text { et al. 2017) }\end{array}$ \\
\hline
\end{tabular}

configuration listed in Table 2, hereafter referred to as BASE. The second simulation is the same as BASE but with all the model developments listed in section 2, hereafter referred to as WACI. The third simulation is the same as WACI but with all (i.e., anthropogenic and natural) aerosol concentrations reduced by $90 \%$, hereafter referred to as LAERO. The fourth and fifth simulations have the same configurations as the WACI and LAERO simulations but utilize the autoconversion parameterization of Liu and Daum (2004, hereafter LD04) in both the gridscale and subgrid-scale microphysics; these simulations are referred to as WACI-LD04 and LAERO-LD04. The evaluation of the BASE and WACI simulations illustrate the performance of the WRF Model with this new configuration and show the difference in model predictions that result from the ACI model developments. The differences between the WACI and LAERO simulations are used to investigate the impact of aerosols on simulated cloud properties, precipitation, and radiation. The differences between the WACI-LD04 and LAEROLD04 simulations are compared against the differences between the WACI and LAERO simulations in order to investigate the uncertainty of ACI introduced by the choice of autoconversion parameterization. The JJA 2006 time period was selected since it is one of the summer periods from the Air Quality Model Evaluation International Initiative phase 2 project (e.g., Campbell et al. 2015) and thus this period has been heavily evaluated by the air quality community.

The use of analysis nudging in WRF-ACI is conceptually similar to the use of the specified dynamics or idealized nudging configurations from global climate models that are considered best practice when simulating aerosol effects (e.g., Kooperman et al. 2012; Ma et al. 2015). However, as noted by Kooperman et al. (2012) nudging may impact model physics in a nontrivial way and thus must be implemented with care. Using nudging for ACI experiments is a trade-off between constraining model errors and dampening aerosol feedbacks. As demonstrated in the work of Otte et al. (2012), without the use of nudging for regional climate simulations the WRF climate will drift, resulting in erroneous climate extremes. Similarly, He et al. (2017) running the same general configuration of WRF over the same time period as this study found that the FDDA-FASDAS nudging configuration was able to significantly reduce accumulated errors in 2-m temperature and reduce a significant dry bias in the central United States. Therefore, it is clear that some nudging constraint is required to keep WRF-ACI from experiencing model biases and climate drift that may impact the validity of the simulations. Kooperman et al. (2012) addressed the trade-off of reduced climate errors and dampened aerosol effects by weakly nudging their aerosol baseline and sensitivity simulations toward an idealized free-run climate simulation using a relaxation coefficient that approximates a time scale of $6 \mathrm{~h}$. This time scale is longer than the lifetime of a cloud and is thus suppressing secondary feedbacks rather than actual ACI radiative forcing (Kooperman et al. 2012). The FDDA free-atmosphere nudging in this work also uses nudging coefficients that approximate a time scale of 6 or $60 \mathrm{~h}$ in the case of moisture, and thus only secondary feedbacks within the free atmosphere will be dampened. However, at the surface FASDAS will constrain temperature and moisture on a much faster time scale. Despite having the potential to overwhelm some aerosol impacts at the surface, the use of FASDAS is important as radiative budget errors within WRF, described in greater detail in section 4 , could allow the sensitivity simulations to drift to a different atmospheric state complicating comparison with the baseline simulations. He et al. (2017) investigated whether or not nudging using FDDA and FASDAS would overwhelm the impact of aerosol effects by computing a pseudoradiative forcing (PRF) based on nudging temperature adjustments and compared those to aerosol radiative forcings (ARFs) available in the literature. They found that while the nudging has the potential to dampen out aerosol effects on a small scale in locations where temperature errors are large, the domain-wide PRF was still smaller than reported ARFs. In the free atmosphere the PRFs were even lower compared to reported ARFs. Therefore, the use of the FDDA-FASDAS nudging configuration to reduce model biases and prevent model drift between sensitivity and baseline simulations is justified despite potential uncertainties. 


\section{b. Evaluation protocol and datasets}

Model performance is evaluated against several observational datasets. Radiative variables including shortwave cloud forcing (SWCF), longwave cloud forcing (LWCF), outgoing longwave radiation at the top of the atmosphere (OLR), and downwelling shortwave radiation at the Earth's surface (SWDOWN) are evaluated against satellite estimates from the Clouds and the Earth's Radiant Energy System/Energy Balanced and Filled (CERES_ EBAF) dataset. Cloud liquid water path (LWP) and cloud fraction (CLDFRA) are evaluated against MODIS level three estimates. Cloud ice water path (IWP) is evaluated against estimates from the European Organisation for the Exploitation of Meteorological Satellites (EUMETSAT) Satellite Application Facility on Climate Monitoring Cloud Albedo and Radiation dataset derived from National Oceanic and Atmospheric Administration-18 (NOAA-18) satellite observations. Last, precipitation is evaluated against estimates from the Parameter-Elevation Regressions on Independent Slopes Model (PRISM) dataset (Daly et al. 1994). None of the parameters evaluated are directly nudged, therefore it can be assumed that they are allowed to freely evolve with the model physics within the restrains of the nudged state variables. However, OLR is related to atmospheric temperature and may be indirectly impacted by the use of nudging.

All satellite and PRISM estimates are regridded from their native resolutions to the WRF domain to facilitate the comparison with the simulated fields. JJA average satellite and simulated fields are compared for radiative variables. LWP and IWP satellite estimates are compared to JJA-averaged simulated fields for only cloudy sky conditions during the time window of 1400-1600 UTC to correspond with the satellite crossing time of the MODIS and NOAA-18 satellites. JJA simulated total precipitation is compared against JJA total estimated precipitation from PRISM. Model performance is gauged based on the comparison of spatial patterns between simulated and estimated fields as well as statically based measures of mean bias (MB), root-mean-square error (RMSE), and Pearson's correlation coefficient $R$.

\section{Model evaluation and comparison}

Model performance statistics for the various meteorological, cloud, and radiative variables mentioned above can be found in Table 3. Overall, Table 3 shows that the WACI and BASE simulations generally predict a similar atmospheric state. The MB and RMSE of LWP and IWP are significantly reduced in the WRF-ACI system, although other variables show slight degradation. It is interesting to note that $R$ values of all evaluated parameters either remain similar or improve in the WACI simulation compared to BASE, except for LWP. Improvements in $R$ values provide some evidence that the use of spatially varying aerosol concentrations and more realistic coupling improves the spatial pattern of simulated radiation, clouds, and precipitation. The reduction in the $R$ value for LWP occurs due to overprediction in LWP in the southern United States, where MSKF has a dominant contribution.

\section{a. Radiation}

JJA averages for several radiative variables $\left(\mathrm{Wm}^{-2}\right)$ from the BASE and WACI simulations are compared against CERES_EBAF estimates in Fig. 1. These are Fig. 1a for longwave cloud forcing (LWCF), Fig. 1b for outgoing longwave radiation (OLR), Fig. 1c for shortwave cloud forcing (SWCF), and Fig. 1d for SWDOWN. BASE and WACI simulations underpredict SWCF (i.e., MBs of -4.1 and $-4.9 \mathrm{~W} \mathrm{~m}^{-2}$, respectively) and LWCF (i.e., MBs of -9.9 and $-13.9 \mathrm{~W} \mathrm{~m}^{-2}$, respectively) compared to CERES_EBAF estimates and subsequently overpredict OLR (i.e., MBs of 5.0 and $9.3 \mathrm{~W} \mathrm{~m}^{-2}$, respectively) and SWDOWN (i.e., MBs 30.3 and $31.5 \mathrm{~W} \mathrm{~m}^{-2}$, respectively). These underpredictions in SWCF and LWCF may also be related to the usage of a very simple subgrid-scale shallow cloud formation scheme when the grid cell relative humidity is less than $100 \%$ in the WRF Model. Thus, incorporation of a robust subgrid-scale shallow cloud formation scheme can be beneficial as demonstrated by Ma et al. (2014) for the simulation of clouds with the WRF-CAM5 configuration compared to the regular WRF Model. Errors in simulated radiation may also be the result of general inaccuracies in WRF simulated cloud coverage and cloud thickness reported in previous studies (e.g., Thompson et al. 2016). The WACI simulation has a slightly greater underprediction of SWCF and moderate LWCF underprediction compared to the BASE simulation. This is a result of coupling cloud drop and ice crystal effective radii from MDM and MSKF to the RRTMG radiation scheme. The values of the effective radii from the MDM and MSKF scheme are generally larger than those prescribed in the RRTMG lookup tables leading to greater radiative transmission. The enhanced SWDOWN from using our methodology is similar to other studies that have coupled cloud effective radii from various microphysics parameterizations to RRTMG in WRF (e.g., Bae et al. 2016; Thompson et al. 2016). The slight degradation of radiation from improved model physics in WACI indicates that tuning parameters in other model physics or dynamics formulations are no longer applicable to the system.

\section{b. Cloud properties}

A comparison of simulated JJA averages of CLDFRA, LWP, IWP, and surface precipitation with those obtained 
TABLE 3. Model performance statistics.

\begin{tabular}{|c|c|c|c|c|c|c|c|c|c|c|}
\hline \multirow[b]{2}{*}{ Variable } & \multirow[b]{2}{*}{ Unit } & \multirow[b]{2}{*}{ Mean obs } & \multicolumn{4}{|c|}{ BASE } & \multicolumn{4}{|c|}{ WACI } \\
\hline & & & Mean model & MB & RMSE & $R$ & Mean model & $\mathrm{MB}$ & RMSE & $R$ \\
\hline LWCF & $\mathrm{W} \mathrm{m}{ }^{-2}$ & 31.0 & 21.2 & -9.9 & 12.0 & 0.52 & 17.1 & -13.9 & 15.2 & 0.53 \\
\hline OLR & $\mathrm{W} \mathrm{m}{ }^{-2}$ & 254.8 & 259.8 & 5.0 & 9.1 & 0.71 & 264.1 & 9.3 & 11.6 & 0.75 \\
\hline SWCF & $\mathrm{W} \mathrm{m}^{-2}$ & -51.6 & -47.5 & -4.1 & 14.1 & 0.64 & -46.7 & -4.9 & 14.8 & 0.67 \\
\hline SWDOWN & $\mathrm{W} \mathrm{m}^{-2}$ & 257.0 & 287.3 & 30.3 & 34.7 & 0.65 & 288.5 & 31.5 & 36.2 & 0.65 \\
\hline LWP & $\mathrm{g} \mathrm{m}^{-2}$ & 134.8 & 77.9 & -56.9 & 72.7 & 0.38 & 108.4 & -26.4 & 57.7 & 0.27 \\
\hline IWP & $\mathrm{g} \mathrm{m}^{-2}$ & 193.3 & 62.9 & -130.5 & 151.1 & 0.01 & 101.0 & -92.3 & 123.7 & 0.03 \\
\hline CLDFRA & $\%$ & 51.0 & 46.3 & -4.8 & 13.4 & 0.56 & 44.8 & -6.2 & 13.9 & 0.58 \\
\hline Precipitation & $\mathrm{mm}$ & 249.5 & 201.1 & -48.4 & 96.7 & 0.76 & 191.2 & -58.3 & 101.2 & 0.78 \\
\hline
\end{tabular}

from MODIS, NOAA-18, and PRISM estimates is shown in Figs. 2a-d. The underpredicted radiation variables shown in Fig. 1 are likely the result of underpredictions in CLDFRA and cloud water (also shown in Table 3). CLDFRA (Fig. 2a) is underpredicted in both the BASE and WACI simulations (i.e., MBs of $-4.8 \%$ and $-6.2 \%$, respectively; Table 3). Underpredictions are the largest across the southeast United States and the northern plains, likely due to an underprediction of cumulus cloud cover. LWP (Fig. 2b) and IWP (Fig. 2c) are largely underpredicted in both the BASE and WACI simulations (i.e., MBs of $-130.5,-92 \mathrm{~g} \mathrm{~m}^{-2}$ and 3-56.9, $-26.4 \mathrm{~g} \mathrm{~m}^{-2}$, respectively; Table 3), with considerable discrepancies in the simulated spatial patterns compared to satellite estimates. Nevertheless, the WACI simulation is relatively better than that of BASE. This type of poor performance compared to satellite estimates is common in many global and regional models and reflects a general issue with the simulation of cloud water that needs to be addressed by the scientific community (e.g., Lauer and Hamilton 2013; Zhang et al. 2012). However, the WACI simulation shows significant improvement in the MB and RMSE of LWP and IWP compared to the BASE simulation.

Differences in LWP, IWP, column-integrated CDNC (CICDNC), column-integrated ice number concentrations (CIINC), and precipitation between the WACI and BASE simulations are respectively shown in Figs. 3a-e. There is no value for subgrid-scale CICDNC and CIINC in the BASE simulation since it does not have any microphysics, therefore the subgrid-scale CICDNC and CIINC plots in Fig. 3 are a representation of the spatial variability in WACI rather than an actual simulated difference. Increases in LWP (Fig. 3a) occur with the WRFACI treatment due to the more realistic subgrid-scale cloud water representation from the modified SZ11 microphysics scheme that increase the subgrid-scale LWP by $8.5 \mathrm{~g} \mathrm{~m}^{-2}$ on domain average and up to $44.5 \mathrm{~g} \mathrm{~m}^{-2}$ in portions of the Southeast and Florida. The Southeast region is also one of the regions with the highest subgridscale CICDNC levels. Gridscale LWP is increased by approximately $2.4 \mathrm{~g} \mathrm{~m}^{-2}$ on domain average and up to over $20 \mathrm{~g} \mathrm{~m}^{-2}$ over the southern plains, portions of the Rocky Mountains, and the Northeast/mid-Atlantic region. The WRF-ACI treatment enhances gridscale CICDNC (Fig. 3c) on domain average by $5.3 \times 10^{14} \mathrm{~cm}^{-2}$. This increase in CICDNC enhances the model's cloud lifetime effect leading to increased LWP.

The Total IWP (Fig. 3b) increases by $13.6 \mathrm{~g} \mathrm{~m}^{-2}$ on domain average between the WACI and BASE simulations due entirely to the increases in gridscale IWP. This unilateral increase in gridscale IWP is the result of the increased $D_{\text {cs }}$ parameter in the WRF-ACI treatment that reduces the removal efficiency of cloud ice. Subgrid-scale IWP declines in the WACI simulation as a result of the changes made to the water and ice fractions following the $\mathrm{Hu}$ et al. (2010) formulation, which parameterizes water and ice fractions based on satellite observations as a function of cloud temperature. The Hu et al. (2010) formulation increased the amount of simulated supercooled liquid water at the expense of the cloud ice and likely also contributes to the large increases in subgrid-scale LWP. The LP05 ice nucleation parameterization used in the WRF-ACI treatment is limited in that it only represents three pathways for ice nucleation from aerosols, unlike in other (e.g., Cooper 1986) ice nucleation parameterizations that are empirically derived functions of temperature representing ice nucleation from all possible sources. As a result, the ice nucleation treatment in WRF-ACI decreases domain average gridscale CIINC (Fig. 3d) by $4.2 \times 10^{12} \mathrm{~cm}^{-2}$. Subgrid-scale ice nucleation appears to be only relevant over the Rockies and the Great Plains, where most of the high-elevation convection occurs.

\section{c. Precipitation}

As discussed earlier, precipitation (Fig. 2d) is underpredicted in both the WACI and the BASE simulations (i.e., MBs of -58.3 and $-48.3 \mathrm{~mm}$, respectively), with the most pronounced underprediction compared to PRISM estimates occurring in the northern plains and Northeast/mid-Atlantic regions. Underpredicted precipitation in the northern plains also occurs in the NAM model used to drive WRF and in many 
BASE
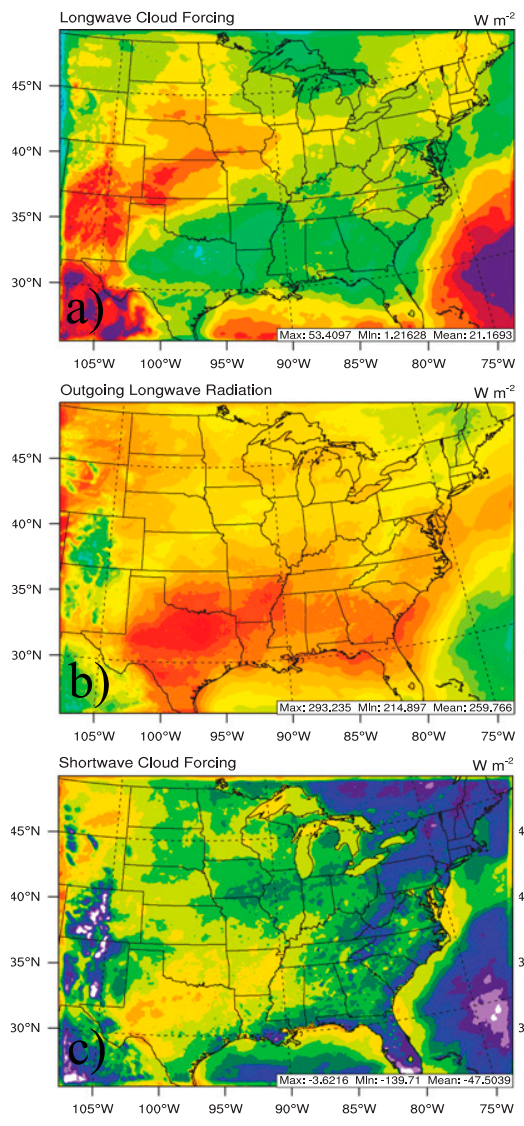

Downwelling Surface Shortwave Radiation

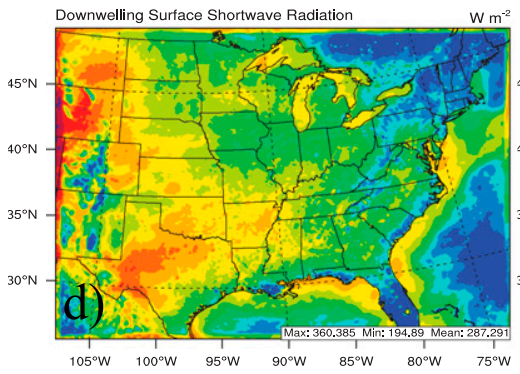

\section{CERES EBAF}
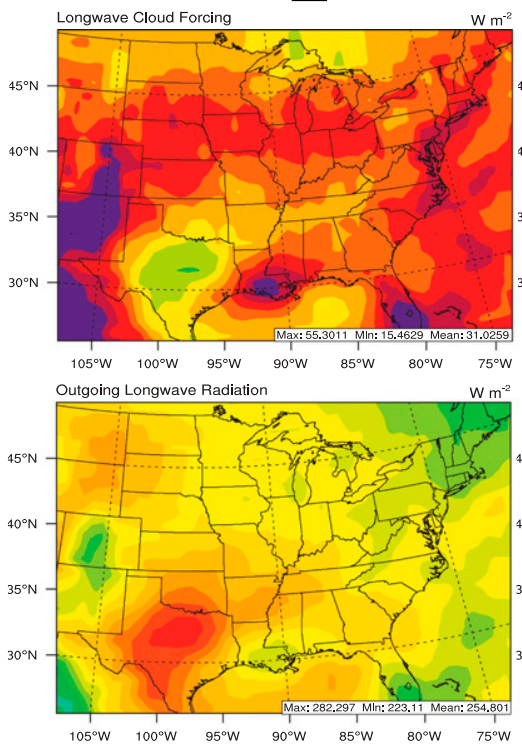

Shortwave Cloud Forcing
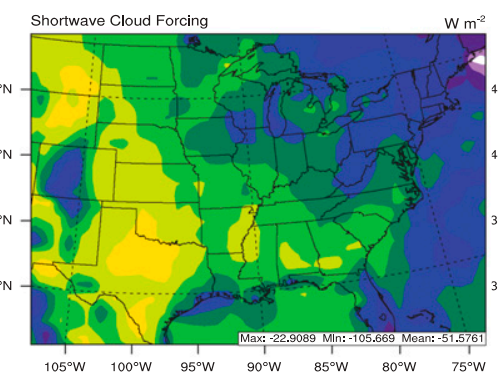

Downwelling Surface Shortwave Radiation

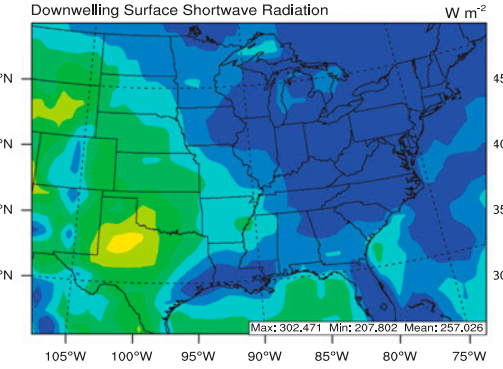

WACI
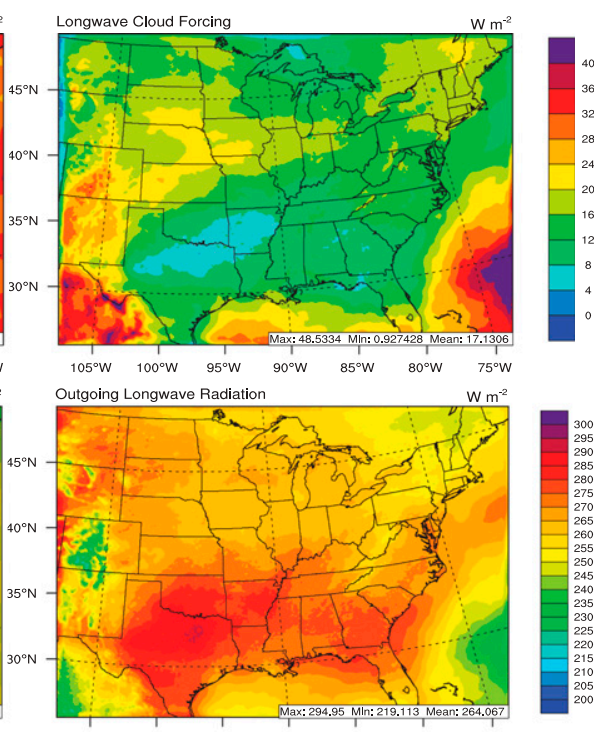

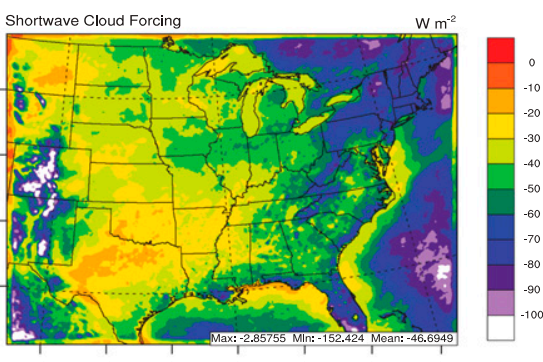

$105^{\circ} \mathrm{W} \quad 100^{\circ} \mathrm{W} \quad 95^{\circ} \mathrm{W} \quad 90^{\circ} \mathrm{W} \quad 85^{\circ} \mathrm{W} \quad 80^{\circ} \mathrm{W} \quad 75^{\circ} \mathrm{W}$

Downwelling Surface Shortwave Radiation

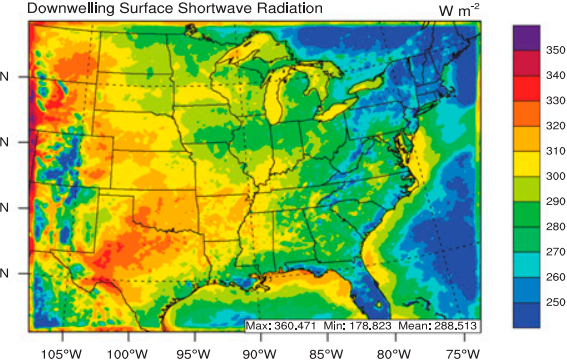

FIG. 1. Spatial distribution of radiative variables from the BASE and WACI simulations compared against CERES_EBAF estimates: (a) longwave cloud forcing, (b) outgoing longwave radiation, (c) shortwave cloud forcing, and (d) downwelling surface shortwave radiation.

global models. The precipitation bias in the NAM has been attributed to the model's inability to adequately simulate the midtropospheric perturbations necessary to induce convection in this region and insufficient atmospheric humidity over the central United States (e.g., Wang et al. 2009). These errors likely propagate to WRF through the initial and boundary conditions or mostly occur within the WRF Model. Total precipitation (Fig. 3e) increases on domain average by $\sim 4.8 \mathrm{~mm}$ due to the WRF-ACI updates, while the changes in the precipitation pattern are complex. Subgrid-scale precipitation is reduced on domain average by $5.9 \mathrm{~mm}$, with much of the reduction occurring over the continental areas of the domain and the largest reduction occurring over the Rockies and the northern plains. However, there are substantial increases in precipitation over the marine portions of the domain. The shift in subgrid-scale precipitation appears to follow atmospheric moisture availability based on the precipitable water vapor plots shown in Fig. S1 of the supplemental material. The shift in subgrid-scale precipitation is likely a consequence of using a microphysics treatment 


\section{BASE}
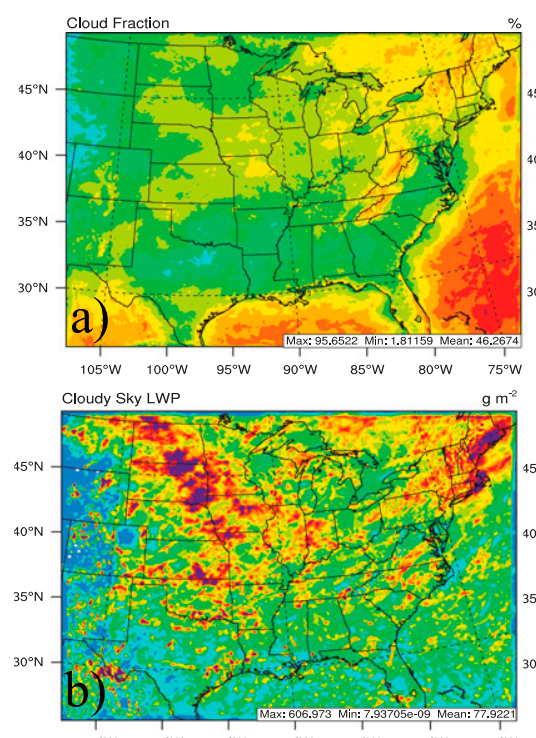

$105^{\circ} \mathrm{W} \quad 100^{\circ} \mathrm{W} \quad 95^{\circ} \mathrm{W} \quad 90^{\circ} \mathrm{W} \quad 85^{\circ} \mathrm{W} \quad 80^{\circ} \mathrm{W} \quad 75^{\circ} \mathrm{W}$

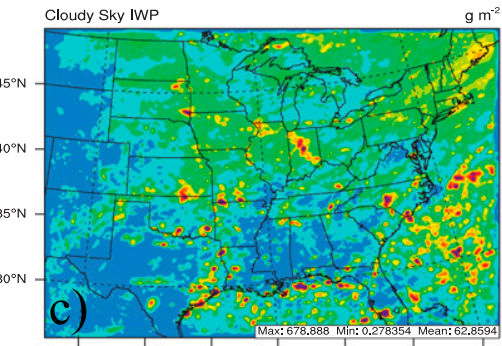

$105^{\circ} \mathrm{W} \quad 100^{\circ} \mathrm{W} \quad 95^{\circ} \mathrm{W} \quad 90^{\circ} \mathrm{W} \quad 85^{\circ} \mathrm{W} \quad 80^{\circ} \mathrm{W} \quad{ }_{75^{\circ} \mathrm{W}}$

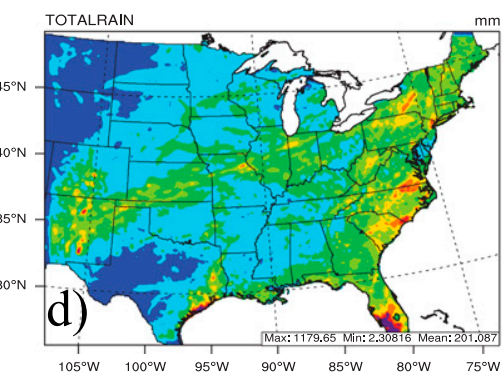

ESTIMATE
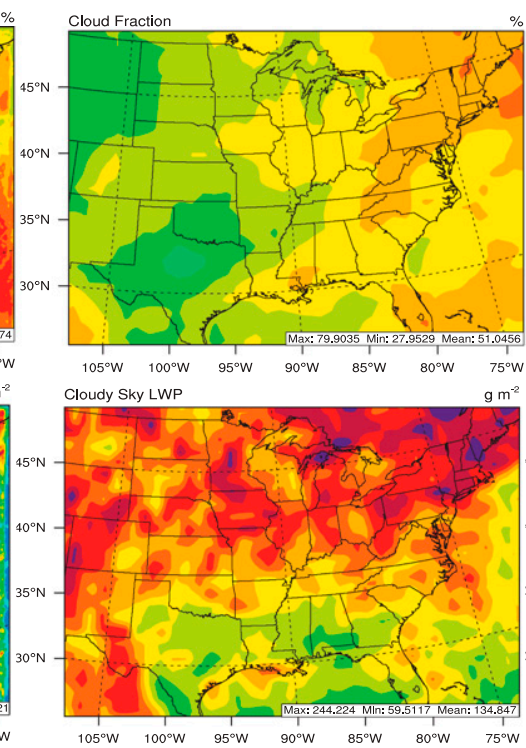

Cloudy Sky IWP

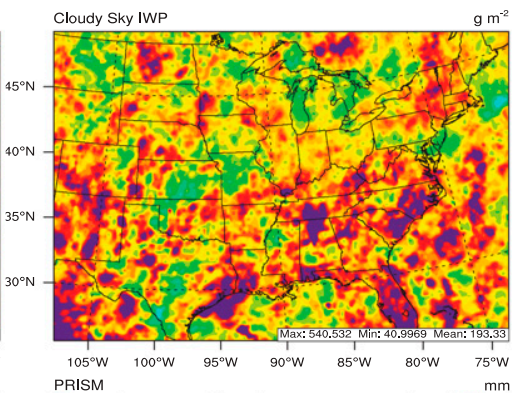

WACI

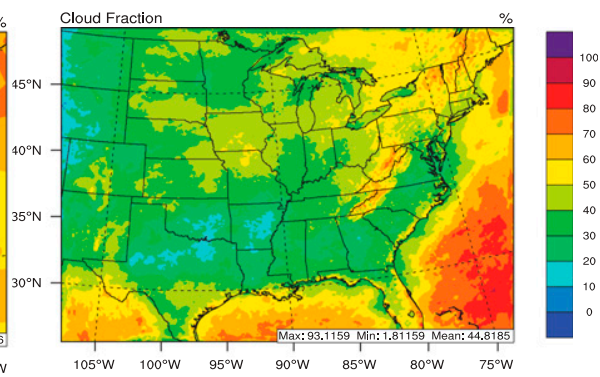

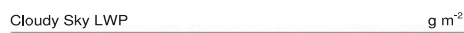

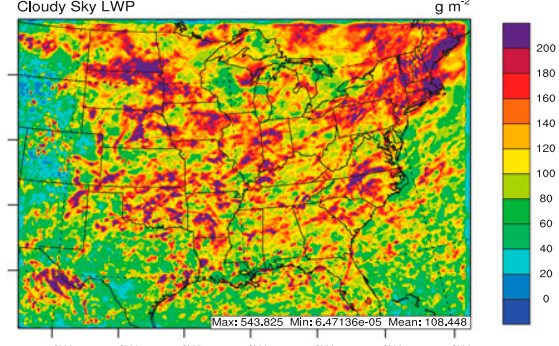

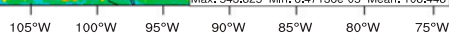

Cloudy Sky IWP
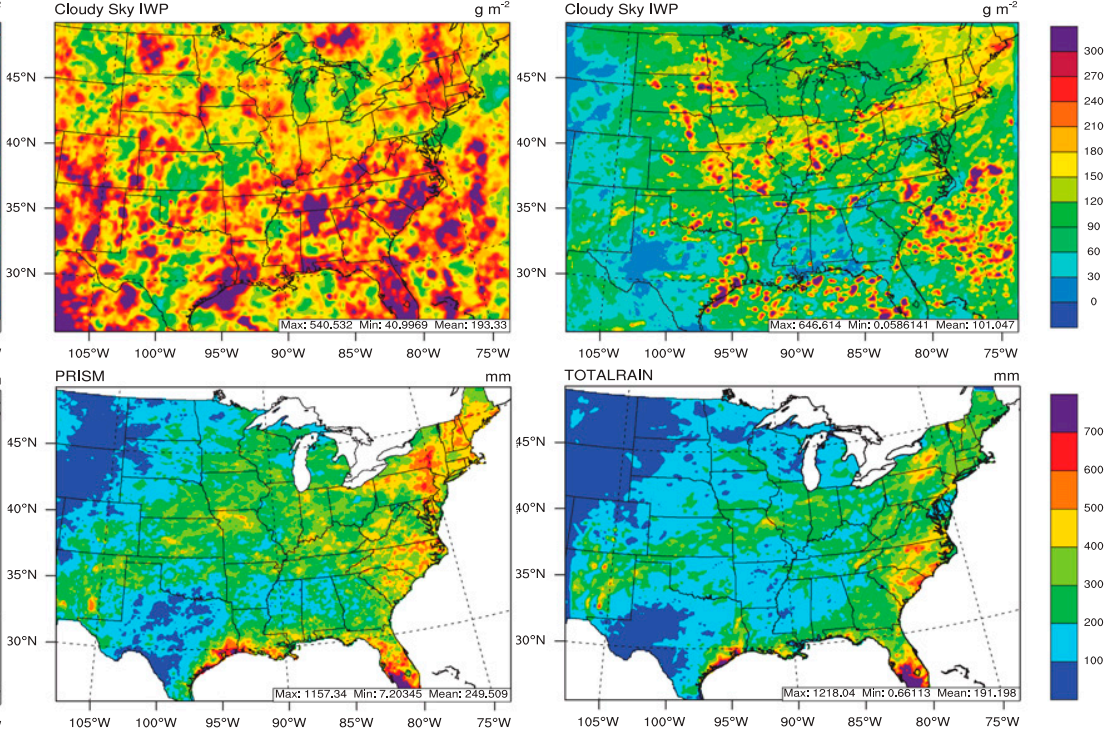

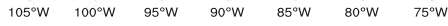

TOTALRAIN

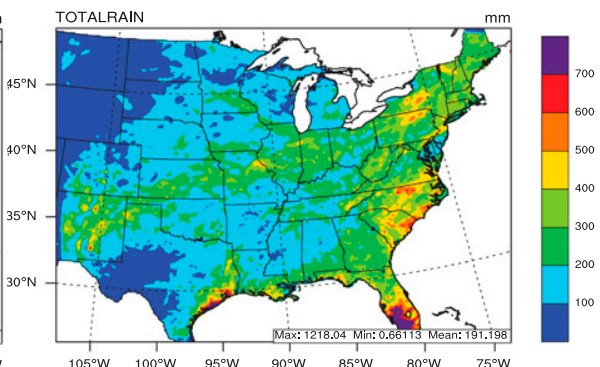

FIG. 2. Spatial distribution of JJA-averaged (a) cloud fraction, (b) LWP, (c) IWP, and (d) precipitation from the BASE and WACR simulations compared to MODIS, NOAA-18, and PRISM estimates.

rather than the default MSKF scheme that diagnoses precipitation triggered by the updraft velocity and buoyancy of an air parcel at the LCL and other associated parameters. This change in precipitation may represent a limitation associated with many microphysics packages, since experiential coefficients in microphysics schemes have large uncertainty and may be different for convective and stratiform clouds and may vary with environmental conditions (Houze 1997; Kogan 2013; Aggarwal et al. 2016).

Gridscale precipitation (Fig. 3e) in WACI is increased on domain average by $\sim 10.7 \mathrm{~mm}$. The pattern of the changes in gridscale precipitation is noisy but there is a notable uniform increase in gridscale precipitation over the northern plains. The increases over the continental areas and especially over the northern plains are likely due to the reduction in activity from MSKF, since both MSKF and MDM compete for the same moisture. Increases in precipitation over the marine portions of the domain most likely occur because of reduced gridscale CICDNC compared the default model that allows for greater precipitation efficiency. However, changes in saturation from thermodynamic perturbations cannot be ruled out. Despite increasing precipitation over the marine regions, the total impact on precipitation over 

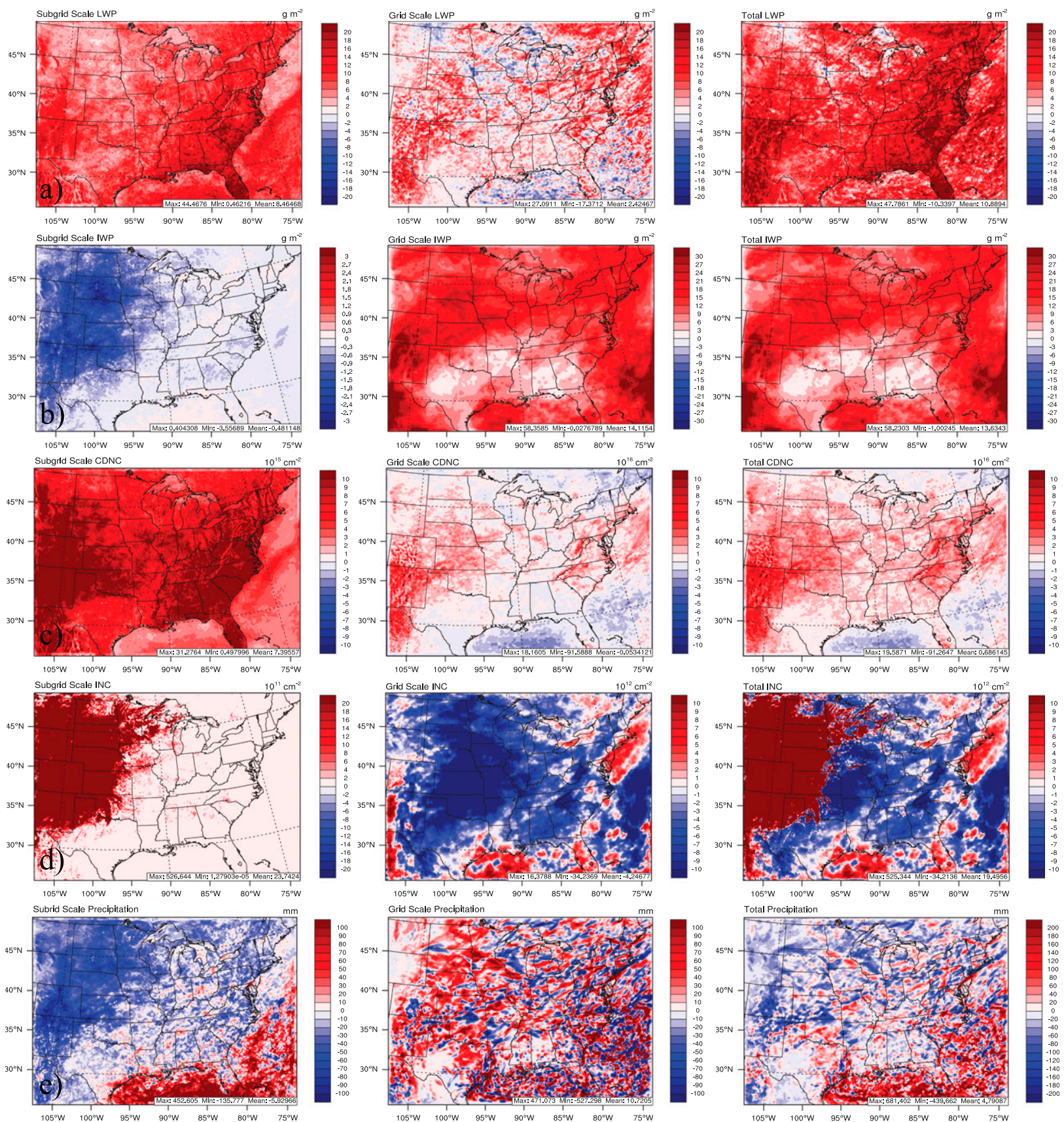

FIG. 3. Differences in (left) subgrid-scale, (center) gridscale, and (right) combined cloud parameters and precipitation between the WACI and BASE simulations: (a) LWP, (b) IWP, (c) CICDNC, (d) CIINC, and (e) surface precipitation.

land is a net decrease which results in an increase of $\sim 10 \mathrm{~mm}$ in the dry bias compared to land-based PRISM estimates.

\section{Aerosol indirect effects}

To study the impacts of aerosols on clouds, as mentioned earlier, we performed another JJA simulation (LAERO) where aerosol concentrations are ad hoc reduced by $90 \%$ as compared to that in the WACI simulation to represent clean conditions. The difference between the WACI and LAERO will enable us to study aerosol indirect effects. Figure 4 shows the difference in subgrid-scale, gridscale, and total LWP, IWP, and precipitation between the WACI and LAERO simulations. Similar differences in subgrid-scale, gridscale, and total CICDNC and CIINC 


\section{Subgrid Scale}
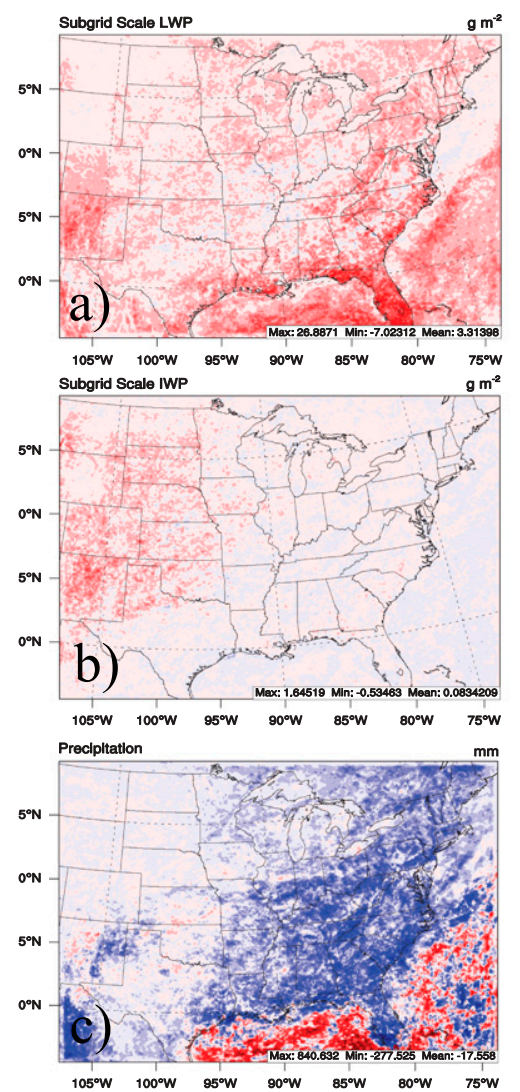

Grid Scale
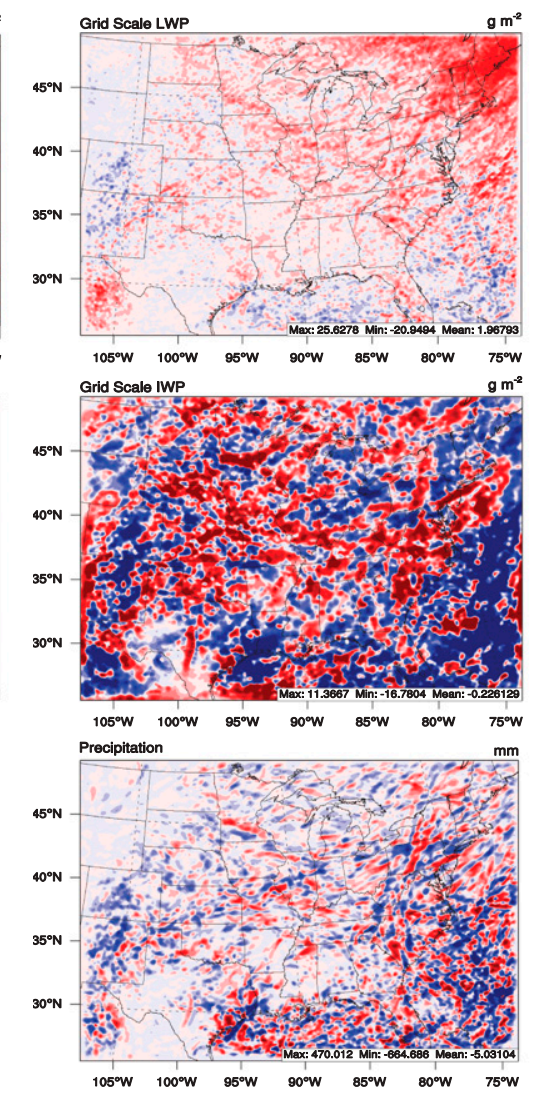

Total
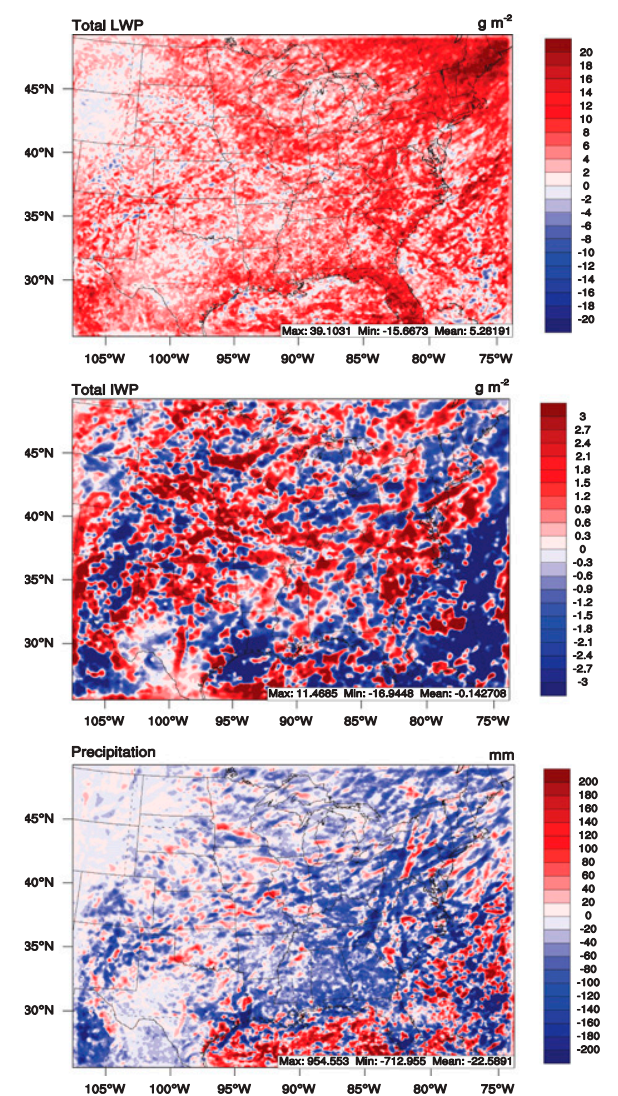

FIG. 4. JJA-averaged differences in (a) LWP, (b) IWP, and (c) precipitation between the WACI and LAERO simulations.

are shown in Fig. S2 of the supplemental material. These difference plots show the LAERO simulation subtracted from the WACI simulations to illustrate the impact of aerosols on the cloud parameters. Therefore, in these figures red colors indicate areas where aerosol effects increase a parameter and blue colors indicate areas where aerosols decrease a parameter.

\section{a. Aerosol impacts on cloud liquid water}

Higher aerosol levels (WACI minus LAERO) lead to generally higher subgrid-scale and gridscale CICDNC levels, increasing the total domain average CICDNC (Fig. S3 of the supplemental material) level by $3.4 \times$ $10^{16} \mathrm{~cm}^{-2}$. The increase in CICDNC from ambient aerosol levels lead to domain average increases in subgridscale, gridscale, and total LWP (Fig. 4a) of $\sim 3.3, \sim 2.0$, and $\sim 5.3 \mathrm{~g} \mathrm{~m}^{-2}$, respectively. This increase in LWP is a result of the cloud lifetime effect. To determine the change in cloud lifetime a similar method to that of $\mathrm{Ma}$ et al. (2015) is used, where the cloud lifetime is defined as the cloud liquid water $\left(\mathrm{g} \mathrm{m}^{-2}\right)$ and rainwater $\left(\mathrm{g} \mathrm{m}^{-2}\right)$ paths divided by the hourly precipitation rate $\left(\mathrm{g} \mathrm{m}^{-2} \mathrm{~h}^{-1}\right)$.
This formulation deviates slightly from Ma et al. (2015), which uses only cloud liquid water path divided by the precipitation rate. Using this formulation, the domain average subgrid-scale cloud lifetime increases from $\sim 1.2 \mathrm{~h}$ in the LAERO simulation to $\sim 2.0 \mathrm{~h}$ with ambient aerosol levels in the WACI simulation. Similarly, for gridscale clouds domain average cloud lifetime increases from $\sim 8.5 \mathrm{~h}$ in the LAERO simulation to $\sim 9.1 \mathrm{~h}$ in the WACI simulation. Thus, the total lifetime of the clouds increased due to increase in the aerosol concentrations.

To analyze the impacts of ACI on LWP the difference in the LWP source term, sink term, and net tendency between the WACI and LAERO simulations from both the subgrid-scale and gridscale clouds are shown in Fig. S3 of the supplemental material. The increase in CICDNC leads to a strong reduction in the subgrid-scale LWP sink terms that consist of autoconversion of cloud drops to rain and accretion of cloud and rain drops. Typically, aerosols have the strongest impact on the autoconversion process and minimal impact on the accretion process (e.g., Ma et al. 2015). But, we find that the accretion process in the subgrid-scale microphysics 
package is heavily impacted by the decline in autoconversion. This coupling of the autoconversion and accretion potentially occurs because the subgrid-scale clouds do not include horizontal transport processes among neighboring grid cells. The strong decline in the subgrid-scale LWP sink terms lead to an increase in the subgrid-scale net LWP tendency, explaining the large increase in subgrid-scale cloud LWP.

The impact of ACI on gridscale cloud LWP is more complex. In the WRF system gridscale microphysics is solved after including the impacts by all other model physics processes on the state of the atmosphere and as a result of this framework the gridscale microphysics is heavily impacted by the effective perturbation by all the other physics processes. This type of modeling methodology leads to a noisy impact in the gridscale LWP source, sink, and net tendency shown in Fig. S3 of the supplemental material. This noisy pattern is consistent in all three terms indicating that model feedbacks from changes in radiation or subgrid-scale ACI dominate over gridscale ACI impacts. However, gridscale ACI likely still play a role since the net tendency for gridscale LWP is positive over much of the domain causing the domain average increase in gridscale LWP. The muted response of the gridscale ACI on LWP is also likely a result of the prognostic rain scheme in MDM, which is not as sensitive to aerosol changes (e.g., Posselt and Lohmann 2009).

\section{b. Impact of aerosols on cloud ice}

The disparity between subgrid-scale and gridscale ACI also occurs with IWP (Fig. 4b). Subgrid-scale IWP increases with greater aerosol levels by $\sim 0.1 \mathrm{~g} \mathrm{~m}^{-2}$ on domain average, while the pattern in gridscale IWP is noisy with a slight domain average decrease of $\sim 0.2 \mathrm{~g} \mathrm{~m}^{-2}$. To analyze the impact of aerosols on IWP the difference in the gridscale and subgrid-scale IWP source, sink, and net tendency terms between the WACI and LAERO simulations are shown in Fig. S4 of the supplemental material. Subgrid-scale IWP sources, sinks, and the net tendency all increase on domain average. This is a result of increases in subgrid IWP propagating into the other terms. Increases in subgridscale IWP sources are potentially related to greater ice deposition or suppression of warm rain formation in the lower part of the cloud that can cause greater amounts of cloud water to be transported above the freezing level. However, compared to MDM, the SZ11 microphysics parameterization uses a simpler method to represent the Bergeron-Findeisen process, which assumes that the cloud liquid water is deposited onto the existing ice crystals when ice water exceeds a threshold value of $0.5 \mathrm{mg} \mathrm{kg}^{-1}$. As a result of this formulation, any increase in subgrid-scale LWP that is caused by aerosols will lead to an increase in subgrid-scale IWP. The pattern in the source, sink, and net tendency terms for gridscale IWP are all noisy in a similar fashion to those from the gridscale LWP, indicating that most of the differences are caused by feedbacks.

\section{c. Impact of aerosols on precipitation}

Domain-averaged differences for the subgrid-scale, gridscale, and total JJA precipitation (Fig. 4c) decrease by $\sim 17.6, \sim 5.0$, and $\sim 22.6 \mathrm{~mm}$, respectively. To further analyze the change in precipitation, the differences in the gridscale and subgrid-scale source, sink, and net tendency terms for rain, snow, and graupel between the WACI and LAERO simulations are shown in supplemental Figs. S5-S7. The gridscale and subgrid-scale net precipitation tendency (i.e., the sum of the net rain, snow, and graupel tendencies) between the WACI and LAERO simulations is shown in Fig. S8 of the supplemental material.

The subgrid-scale suppression of precipitation by aerosols occurs largely over the continental portion of the domain due to the reduction in subgrid-scale rain sources by reduced autoconversion and accretion of cloud water. Subgrid-scale rain sinks and the net tendency are also mostly negative, except for rain sinks over the oceanic portions of the domain. It is important to note that in the context of this paper, sinks for rain, snow, and graupel do not include fallout terms and the fallout terms are implicitly assumed to be reflected in the changes in precipitation. The increase in the subgridscale rain sink over the oceans is due to the collision and collection of rain drops by ice and snow crystals leading to a net increase in the snow production rate shown in Fig. S7 of the supplemental material. In the SZ11 microphysics scheme there are no sinks for snow (since fallout is not considered a sink), therefore, the snow source term and net tendency are identical. The increase in snow production is dominated by accretion of cloud droplets by snow over land (e.g., TE14), likely in response to the cloud lifetime effect, and the collection of rain drops by snow over the marine regions. These findings are similar to both TE14 and Igel et al. (2013) that have shown increased precipitation from higher aerosol levels in mixed phase clouds, resulting from greater accretion of rain and clouds droplets by snow. The increase in snow production from the collection of rain drops by snow in the moist oceanic environment is responsible for the enhanced marine subgrid-scale precipitation. The net precipitation tendency is negative for most of the domain, with an exception to some oceanic locations. The spatial pattern of this tendency is not an exact match to the change in total precipitation likely because of other processes impacting subgrid-scale precipitation that are outside of the microphysics in MSKF, 
such as evaporation/sublimation of rain/snow, or variability in precipitation intensity during the JJA period.

Changes in gridscale precipitation are again subject to many model perturbations. In general, the spatial patterns of the changes in sources, sinks, and net tendencies are similar for the gridscale rain, snow, and graupel hydrometeor classes. The source and sink terms for all three gridscale precipitation types decrease on domain average, which does indicate gridscale ACI that suppresses precipitation. Interestingly, the domain average sink terms for all three hydrometeor classes decrease in magnitudes larger than the domain average source terms. Since the sink terms for these hydrometeor classes only represent transformations between these hydrometeor types and evaporation/sublimation, it can be reasonably assumed that these decreases in sinks are caused by reductions in evaporation/sublimation. The decrease in the rain sink term is large compared to the decrease in the rain sources resulting in a positive domain average rain tendency that dominates the gridscale net precipitation tendency shown in Fig. S8. Despite the positive net precipitation tendency, the domain average change in gridscale precipitation is still negative, while there are many locations with increased precipitation including the Midwest. The reduction in evaporation/ sublimation that causes the increased precipitation in many areas is likely caused by a moistening of the environment from both the gridscale and subgrid-scale cloud lifetime effects. This is because longer cloud lifetimes reduce radiation reaching Earth's surface cooling the environment and the reduced precipitation efficiency, especially in the subgrid scale, allow more moisture to be retained in the atmosphere.

\section{d. Impact of aerosols on cloud height and coverage}

To further explore the impact of the aerosol indirect effects the differences in deep convective cloud fraction (DCCF), total cloud fraction, and subgrid-scale and gridscale cloud-top heights between the WACI and LAERO simulations are shown in Fig. 5. It is important to note that the gridscale cloud-top height in these figures represents only warm clouds or mix phase clouds but not ice clouds such as cirrus. The DCCF absolute value increases on domain average by $\sim 2.4 \times 10^{-5} \%$ (which amounts to a relative increase of $\sim 0.9 \%$ ), while the total cloud fraction declines on domain average by $\sim 0.5 \%$. The total cloud fraction decreases the most over the southern plains and over the marine portion of the domain, while there are increases in cloud fraction over much of the remaining continental areas. The increases in cloud fraction over the continental areas are consistent with the cloud lifetime effect, as the moistening of the atmosphere and longer cloud lifetime should increase the cloud coverage for sustained thermodynamic conditions. The decreases in saturation over the oceanic regions may also be related to sea-salt ACI, since seasalt aerosols have been shown to suppress in-cloud supersaturation due to their significant ability to uptake water (e.g., Partanen et al. 2014). A similar pattern occurs for the DCCF although increases in land cloud coverage compensate the declines over the ocean. DCCF is slightly different from total cloud fraction as the cloud fraction from MSKF is a function of the convection strength. Thus, the increases in DCCF are likely related either to thermodynamic invigoration from aerosols or changes in convective state of the atmosphere. Both gridscale and subgrid-scale cloud-top heights increase due to aerosols by $\sim 2.4 \mathrm{~m}$ and $\sim 11.0 \mathrm{~m}$ on domain average, respectively (for an average layer thickness of $\sim 500-600 \mathrm{~m}$ ). Increases in subgrid and gridscale cloudtop heights occur even in regions where cloud fractions decline, indicating that the clouds are invigorated even though the cloud coverage is reduced. The only exceptions are decreases in cloud-top heights over the oceanic regions that are consistent with the decline in cloud fraction from either thermodynamic feedbacks or seasalt ACI. The increases in cloud-top heights over a majority of the domain provides some evidence that the thermodynamic invigoration effect is occurring, while other factors such as thermodynamic feedbacks and the cloud lifetime effect have a stronger impact on cloud water, cloud ice, and precipitation.

\section{e. Impact of aerosols on radiation}

Differences in SWCF and LWCF between the WACI and LAERO simulations are shown in Fig. 6. SWCF increases nearly everywhere in the domain with a domain average increase of $\sim 3.0 \mathrm{~W} \mathrm{~m}^{-2}$. The increase in SWCF results from a combination of the cloud lifetime and albedo effects as the higher LWP from the cloud life effects and the smaller droplet size from the cloud albedo effect result in greater reflectance of the clouds. There are some decreases in SWCF that occur over the oceanic areas, likely associated with the reduction in cloud fraction. The impact on LWCF is more complex with a domain average reduction of $\sim 0.2 \mathrm{~W} \mathrm{~m}^{-2}$. The largest reductions occur in the southern plains and the marine portions of the domain, with the spatial pattern mirroring the changes in both cloud fraction and IWP.

\section{Sensitivity of aerosol indirect effects to autoconversion schemes}

The autoconversion parameterization in cloud microphysical schemes represents a large source of uncertainty for simulating ACI (e.g., Penner et al. 2006; 

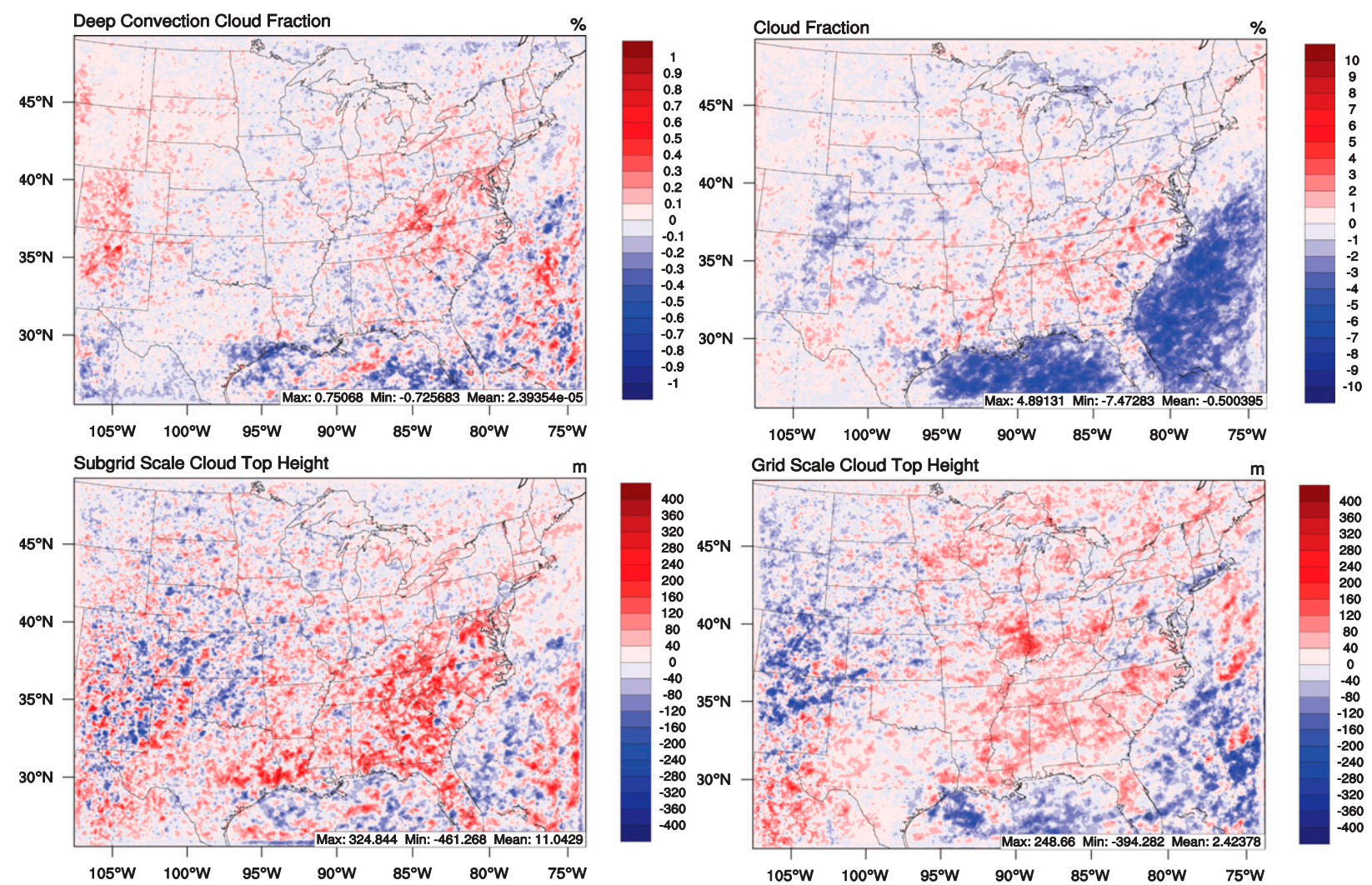

FIG. 5. Differences in deep convective cloud fraction, total cloud fraction, and subgrid-scale and gridscale cloud-top height between the WACI and LAERO simulations.

Tonttila et al. 2015; Xie and Liu 2015; White et al. 2017). To further explore this uncertainty, additional WACI and LAERO seasonal simulations are conducted by implementing the autoconversion parameterization of LD04 into both MDM and MSKF as a second option to choose from. These simulations are hereafter referred to as WACI-LD04 and LAERO-LD04. The difference in subgrid-scale, gridscale, and total LWP, IWP, and precipitation between the WACI-LD04 and LAERO-LD04 simulations is shown in Fig. 7.

The LD04 parameterization requires a cloud droplet radius to reach a threshold value of $15 \mu \mathrm{m}$ before the autoconversion process begins. This differs from the empirically derived Khairoutdinov and Kogan (2000) and Kogan (2013) (KK0013) parameterizations that essentially allow autoconversion to begin once cloud water has formed. Therefore, the autoconversion process in the WACI-LD04 and LAER-LD04 simulations is essentially slower than the WACI and LAERO simulations. The slower autoconversion process in the LD04 simulations has a substantial impact on the cloud lifetime effect as the domain average subgrid-scale LWP is enhanced by $8.96 \mathrm{~g} \mathrm{~m}^{-2}$ between the WACI-LD04 and LAEROLD04 simulations (Fig. 7a), which is more than double the subgrid-scale LWP enhancement between the WACI and LAERO simulations (Fig. 4a). The impact of numerical perturbations on gridscale LWP is even larger in the LD04 simulations compared to the KK0013 simulations. The smaller gridscale cloud lifetime effect in the LD04 simulations are driven by reductions in gridscale LWP. The substantial increase in subgrid-scale LWP and the reduced gridscale LWP likely indicates that one of the major feedbacks driving the noisy impact of the gridscale clouds is competition for available moisture between both the gridscale and subgrid-scale parameterizations (i.e., more moisture retained by the subgrid clouds means less is available for the gridscale clouds). Overall, the impact of aerosols on total LWP in the LD04 simulations (Fig. 7a) is much larger than that in the impact in the KK0013 simulations (Fig. 4a), especially in the Southeast and Maine.

Differences in IWP between the WACI-LD04 and LAERO-LD04 simulations (Fig. 7b) are qualitatively similar to those between the WACI and LAERO simulations (Fig. 4b). The domain average enhancement of subgrid-scale IWP also more than doubles in the LD04 simulations to $\sim 0.24 \mathrm{~g} \mathrm{~m}^{-2}$. This confirms to some extent that the subgrid-scale IWP increases are directly 

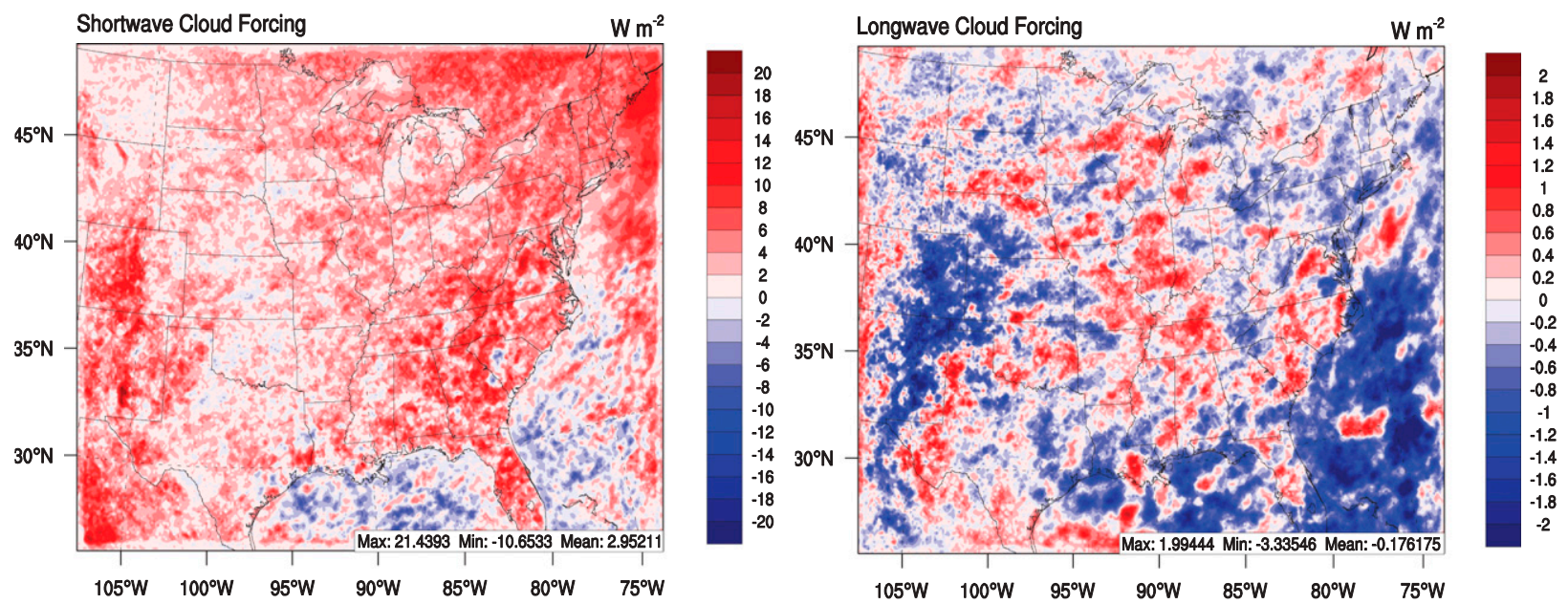

FIG. 6. Differences in shortwave cloud forcing and longwave cloud forcing between the WACI and LAERO simulations.

related to the Bergeron-Findeisen parameterization in SZ11, mentioned in section 5b. The LD04 gridscale IWP differences contain a similar noisy pattern as the KK0013 simulations, however, one feature of the LD04 simulations is that gridscale IWP is generally more enhanced in the eastern United States and reduced in the Great Plains due to aerosols. Overall, gridscale IWP is reduced to a lesser extent and subgrid-scale IWP is enhanced to a greater extent in the LD04 simulations resulting in an average increase in total IWP from aerosols using the LD04 parameterization.
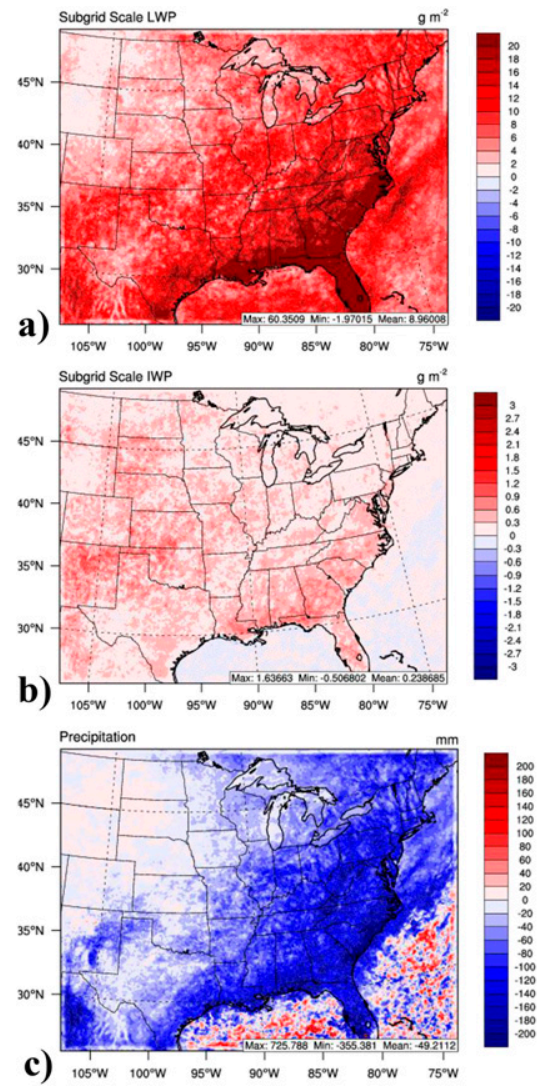
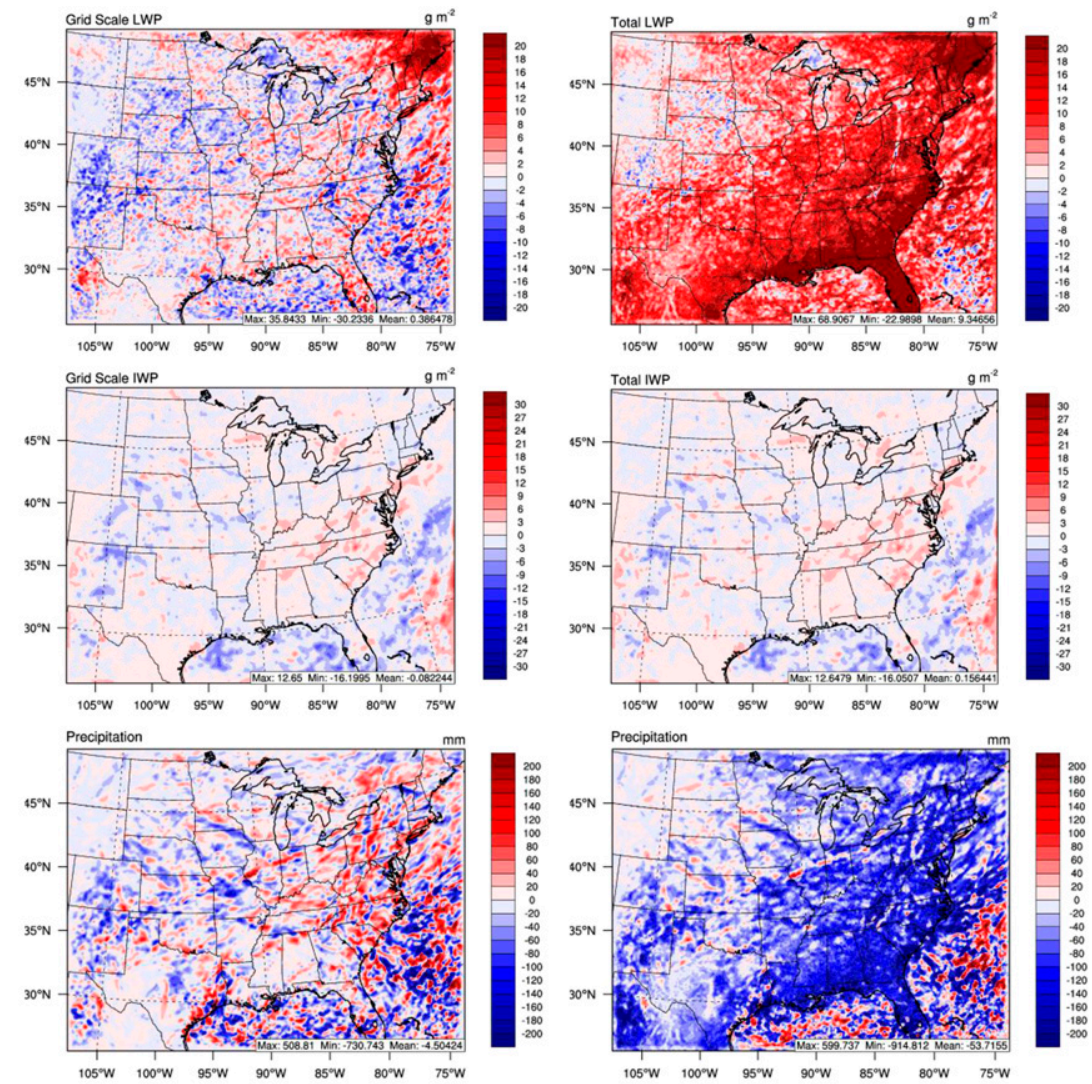

FIG. 7. JJA-averaged differences in (a) LWP, (b) IWP, and (c) precipitation between the WACI-LD04 and LAERO-LD04 simulations. 
Differences in precipitation between the WACILD04 and LAERO-LD04 simulations (Fig. 7c) are also qualitatively similar to the differences between the WACI and LAERO simulations (Fig. 4c). In the LD04 simulations, subgrid-scale precipitation is significantly and more consistently reduced over the continental portions of the domain with a domain average reduction of $\sim 48.2 \mathrm{~mm}$. This is significantly larger than the $\sim 17.6 \mathrm{~mm}$ domain average reduction in the KK0013 simulations. The noisy patterns and domain mean reductions in gridscale precipitation are similar in both the LD04 $(\sim 4.5 \mathrm{~mm})$ and KK0013 $(\sim 5.0 \mathrm{~mm})$ simulations, as a result, the dramatic decrease in subgrid-scale precipitation dominates the total precipitation change in the LD04 simulations, especially in the Southeast.

The LD04 sensitivity experiments indicate that the choice of autoconversion scheme has much more significant impact on subgrid-scale ACI compared to gridscale ACI. This is consistent with the findings from section 5 that showed a stronger sensitivity of subgridscale clouds to aerosol loadings. The LD04 parameterization largely amplifies the impact of ACI due to having a more stringent requirement for when the autoconversion process is triggered. Generally, it would appear that for this JJA 2006 case the choice of autoconversion parameterization can result in sizable differences in magnitude of ACI, but the overall ACI patterns and conclusions remain the same.

\section{Summary and conclusions}

In this work the WRF 3.8.1 model has been further developed to include a computationally efficient physics package for simulating aerosol-cloud interactions (WRF-ACI). The WRF-ACI system includes 1) the implementation of a subgrid-scale microphysics parameterization into the MSKF cumulus parameterization, 2) the incorporation of aerosol activation and ice nucleation parameterizations into the gridscale microphysics (MDM) scheme consistent with that in the MSKF scheme, 3) coupling of the MSKF and MDM microphysics to the RRTMG radiation scheme to simulate aerosol indirect effects, and 4) a spatially and temporally varying aerosol climatology from CESM-NCSU with bias correction to facilitate aerosol-cloud-radiation interactions.

Results indicate that introducing ACI to the WRF Model impacts nearly all cloud and radiation related parameters. The WRF-ACI system has improved LWP and IWP performance in terms of MB and RMSE compared to the default WRF Model, but has similar or slightly degraded performance in SWCF, LWCF, SWDOWN, OLR, and precipitation. The $R$ values of all evaluated parameters either remain similar or improve compared to the default WRF Model, except for LWP. This may indicate that the spatially and temporally varying aerosols within the WRF-ACI treatment lead to improvements in simulated spatial patterns, however, these improvements may not be statistically significant. Also, the overall simulated impact of aerosols on radiation, clouds, and precipitation using the new ACI capabilities is strongly modulated by the details of the subgrid-scale microphysics scheme, and perhaps to a lesser extent by the hosting subgrid-scale convection scheme. Further, it is worthy to note that underpredictions in cloud radiative forcing result from general deficiencies in cloud microphysics parameterizations used in many regional and global models that have issues simulating cloud heights, thickness, and cloud liquid and ice water paths. Precipitation biases exist in both model configurations due potentially to biases in the NAM reanalysis moisture fields and the inability of the model to accurately represent the processes for convection.

We found that the first version of the WRF-ACI model can be used to study the impacts of aerosol loading levels. Comparisons between the WACI (with current climate aerosol loading) and LAERO (with $90 \%$ reduction in aerosol loading) simulations show a strong cloud lifetime effect from ambient aerosols in the central and eastern United States that increase JJA 2006 average LWP by $\sim 5.3 \mathrm{~g} \mathrm{~m}^{-2}$ and decrease cumulative precipitation by $\sim 22.6 \mathrm{~mm}$ on domain average. Increases in cloud-top heights and DCCF over most of the domain indicate a thermodynamic invigoration effect, but the impact of this effect on precipitation is overwhelmed by the cloud lifetime effect. The combined cloud lifetime effect and cloud albedo effect increase JJA average SWCF over the central and eastern United States by $\sim 3.0 \mathrm{~W} \mathrm{~m}^{-2}$, while LWCF declines by $\sim 0.2 \mathrm{~W} \mathrm{~m}^{-2}$ resulting largely from thermodynamic feedback driven changes in cloud coverage and IWP.

The WACI-LD04 and LAERO-LD04 simulations reveal that the magnitude of ACI, especially in the subgrid-scale clouds can be significantly impacted by the choice of autoconversion parameterization. The enhanced ACI in the LD04 simulations likely indicates that the threshold value for the triggering autoconversion has a significant impact on ACI, where the more stringent the threshold the greater the impact of ACI. Despite the large differences in magnitude, for the JJA 2006 case investigated in this study, it does not appear that the choice of autoconversion parameterization has a substantial impact on the conclusion of the WRF-ACI experiments, since the spatial patterns in ACI between the LD04 and KK0013 simulations were qualitatively similar. 
In the WRF-ACI system experiments conducted here aerosols have a strong impact on subgrid-scale clouds, while gridscale cloud parameters are impacted more by thermodynamic feedback and perturbations at $12-\mathrm{km}$ grid spacing. The muted impact of ACI on gridscale clouds shown in this study does not necessarily suggest that gridscale clouds have weaker ACI compared to subgrid-scale clouds. Rather, the findings of this study suggest that gridscale ACI can become overwhelmed by the competition between the gridscale and subgrid-scale parameterizations at $12-\mathrm{km}$ grid spacing. The way ACI is treated between the subgrid-scale clouds and gridscale clouds and some of the degraded model performance issues indicated a need for further improvements to the WRF as well as the WRF-ACI system. One such improvement can be made by providing the same state of the atmosphere to the gridscale microphysics the same way as for the rest of the physical processes. Thus, such model configuration factors (that are difficult to change) can be attributed to some degradation in model performance of the WRF-ACI system simulations. This research represents a first step toward a realistic representation of subgrid-scale microphysics processes and ACI across scales that can be refined as new science emerges. The WRF-ACI system also allows for the study of the scale dependence of ACI, which will be presented in a subsequent publication by using different grid spacing ranging from 36 to $1 \mathrm{~km}$ within the gray zone.

Acknowledgments. Thanks are due to Dr. Yang Zhang of North Carolina State University for providing the aerosol data for the CESM-NCSU aerosol climatology. Authors thank anonymous reviewers and EPA's internal reviewers, Drs. Chris Weaver and Brett Gantt for providing us with valuable comments on this work. This document has been reviewed by the U.S. Environmental Protection Agency, Office of Research and Development, and approved for publication. The views expressed in this paper are those of the authors and do not necessarily reflect the views or policies of the U.S. Environmental Protection Agency. All data used to generate figures and tables shown in this article can be freely downloaded at https://edg.epa.gov/metadata/catalog/ main/home.page.

\section{REFERENCES}

Abdul-Razzak, H., and S. J. Ghan, 2000: A parameterization of aerosol activation: 2. Multiple aerosol types. J. Geophys. Res., 105, 6837-6844, https://doi.org/10.1029/1999JD901161.

Aggarwal, P. K., U. Romatschke, L. Arguas-Arguas, D. Belachew, F. J. Longstaffe, P. Berg, C. Schumacher, and A. Funk, 2016: Proportions of convective and stratiform revealed in water isotope ratios. Nat. Geosci., 9, 624-629, https://doi.org/10.1038/ngeo2739.
Alapaty, K., D. Niyogi, F. Chen, P. Pyle, A. Chandrasekar, and N. Seaman, 2008: Development of the flux-adjusting surface data assimilation system for mesoscale models. J. Appl. Meteor. Climatol., 47, 2331-2350, https://doi.org/10.1175/2008JAMC1831.1.

_ J. A. Herwehe, T. L. Otte, C. G. Nolte, O. R. Bullock, M. S. Mallard, J. S. Kain, and J. Dudhia, 2012: Introducing subgridscale cloud feedbacks to radiation for regional meteorological and climate modeling. Geophys. Res. Lett., 39, L24809, https:// doi.org/10.1029/2012GL054031.

_ J. S. Kain, J. S. Herwehe, O. R. Bullock, M. S. Mallard, T. L. Spero, and C. G. Nolte, 2014: Multiscale Kain-Fritsch scheme: Formulations and tests. 13th Annual CMAS Conf., Chapel Hill, NC, University of North Carolina, https://www.cmascenter.org/ conference/2014/agenda.cfm\#inline1503.

Albrecht, B. A., 1989: Aerosols, cloud microphysics, and fractional cloudiness. Science, 245, 1227-1230, https://doi.org/10.1126/ science.245.4923.1227.

Bae, S. Y., S.-Y. Hong, and K.-S. S. Lim, 2016: Coupling WRF double-moment 6-class microphysics schemes to RRTMG radiation scheme in Weather Research Forecasting Model. Adv. Meteor., 2016, 5070154, https://doi.org/10.1155/2016/ 5070154.

Bender, F. A.-M., 2012: Aerosol forcing: Rappoteur's report and summary. Surv. Geophys., 33, 693-700, https://doi.org/ 10.1007/s10712-011-9160-0.

Bergeron, T., 1935: On the physics of clouds and precipitation. Proces Verbaux de l'Association de Météorologie, International Union of Geodesy and Geophysics, 156-178.

Boucher, O., and Coauthors, 2013: Clouds and aerosols. Climate Change 2013: The Physical Science Basis, T. F. Stocker et al., Eds., Cambridge University Press, 571-657.

Bullock, O. R., K. Alapaty, J. A. Herwehe, M. S. Mallard, T. L. Otte, R. C. Gilliam, and C. G. Nolte, 2014: An observationbased investigation of nudging in WRF for downscaling surface climate information to $12-\mathrm{km}$ grid spacing. J. Appl. Meteor. Climatol., 53, 20-33, https://doi.org/10.1175/JAMC-D-13-030.1.

Campbell, P., and Coauthors, 2015: A multi-model assessment for the 2006 and 2010 simulations under the Air Quality Model Evaluation International Initiative (AQMEII) phase 2 over North America: Part I. Indicators of the sensitivity of $\mathrm{O}_{3}$ and $\mathrm{PM}_{2.5}$ formation regimes. Atmos. Environ., 115, 569-586, https:// doi.org/10.1016/j.atmosenv.2014.12.026.

Chen, F., and J. Dudhia, 2001: Coupling an advanced land-surface/ hydrology model with the Penn State/US7 MM5 modeling system. Part I: Model implementation and sensitivity. Mon. Wea. Rev., 129, 569-585, https://doi.org/10.1175/1520-0493(2001) 129<0569:CAALSH $>2.0 . \mathrm{CO} ; 2$.

Clough, S. A., M. W. Shephard, J. E. Mlawer, J. S. Delamere, M. J. Iacono, K. Cady-Pereira, S. Boukabara, and P. D. Brown, 2005: Atmospheric radiative transfer modeling: a summary of the AER codes. J. Quant. Spectrosc. Radiat. Transfer, 91, 233-244, https://doi.org/10.1016/j.jqsrt.2004.05.058.

Colarco, P., A. da Silva, M. Chin, and T. Diehl, 2010: Online simulations of global aerosol distributions in the NASA GEOS-4 model and comparisons to satellite and ground-based aerosol optical depth. J. Geophys. Res., 115, D14207, https://doi.org/ 10.1029/2009JD012820.

Cooper, W. A., 1986: Ice initiation in natural clouds. Precipitation Enhancement-A Scientific Challenge, Meteor. Monogr., No. 21, Amer. Meteor. Soc., 29-32.

Daly, C., R. P. Neilson, and D. L. Phillips, 1994: A statisticaltopographic model for mapping climatological precipitation over mountainous terrain. J. Appl. Meteor., 33, 140-158, 
https://doi.org/10.1175/1520-0450(1994)033<0140:ASTMFM> 2.0.CO;2.

DeMott, P. J., and Coauthors, 2010: Predicting global atmospheric ice nuclei distributions and their impacts on climate. Proc. Natl. Acad. Sci. USA, 107, 11217-11222, https://doi.org/ 10.1073/pnas.0910818107.

Denman, K. L., and Coauthors, 2007: Couplings between changes in the climate system and biogeochemistry. Climate Change 2007: The Physical Science Basis, S. Solomon et al., Eds., Cambridge University Press, 499-587.

Ek, M. B., K. E. Mitchell, Y. Lin, E. Rogers, P. Grunmann, V. Koren, G. Gayno, and J. D. Tarpley, 2003: Implementation of Noah land surface model advances in the National Centers for Environmental Prediction operational mesoscale Eta model. J. Geophys. Res., 108, 8851, https://doi.org/10.1029/ 2002JD003296.

Findeisen, W., 1938: Kolloid-meteorologische Vorgänge bei Neiderschlags-bildung. Meteor. Z., 55, 121-133.

Gantt, B., J. He, X. Zhang, Y. Zhang, and A. Nenes, 2014: Incorporation of advanced aerosol activation treatments into CESM/CAM5: Model evaluation and impact on aerosol indirect effects. Atmos. Chem. Phys., 14, 7485-7497, https://doi.org/ 10.5194/acp-14-7485-2014.

Glotfelty, T., J. He, and Y. Zhang, 2017a: Improving organic aerosol treatments in CESM/CAM5: Development, application, and evaluation. J. Adv. Model. Earth Syst., 9, 1506-1539, https://doi.org/10.1002/2016MS000874.

,$- \ldots$, and $-2017 \mathrm{~b}$ : The impact of future climate policy scenarios on air quality and aerosol/cloud interactions using an advanced version of CESM/CAM5: Part I. Model evaluation for the current decadal simulations. Atmos. Environ., 152, 222-239, https://doi.org/10.1016/j.atmosenv.2016.12.035.

Grell, G. A., and S. R. Freitas, 2014: A scale and aerosol aware stochastic convective parameterization for weather and air quality modeling. Atmos. Chem. Phys., 14, 5233-5250, https:// doi.org/10.5194/acp-14-5233-2014.

—, S. E. Peckham, R. Schmitz, S. A. McKeen, G. Frost, W. C. Skamarock, and B. Eder, 2005: Fully coupled online chemistry within the WRF model. Atmos. Environ., 39, 6957-6975, https://doi.org/10.1016/j.atmosenv.2005.04.027.

He, J., and Y. Zhang, 2014: Improvement and further development in CESM/CAM5: Gas-phase chemistry and inorganic aerosol treatments. Atmos. Chem. Phys., 14, 9171-9200, https://doi.org/ 10.5194/acp-14-9171-2014.

_, T. Glotfelty, K. Yahya, K. Alapaty, and S. Yu, 2017: Does temperature nudging overwhelm aerosol radiative effects in regional integrated climate models? Atmos. Environ., 154, 42-52, https://doi.org/10.1016/j.atmosenv.2017.01.040.

Hong, S.-Y., and J. Dudhia, 2012: Next-generation numerical weather prediction: Bridging parameterization, explicit clouds, and large eddies. Bull. Amer. Meteor. Soc., 93, ES6-ES9, https://doi.org/10.1175/2011BAMS3224.1.

—, Y. Noh, and J. Dudhia, 2006: A new vertical diffusion package with an explicit treatment of entrainment processes. Mon. Wea. Rev., 134, 2318-2341, https://doi.org/10.1175/ MWR3199.1.

Houze, R. A., Jr., 1997: Stratiform precipitation in regions of convection: a meteorological paradox? Bull. Amer. Meteor Soc., 78, 2179-2196, https://doi.org/10.1175/1520-0477(1997) $078<2179$ :SPIROC $>2.0 . \mathrm{CO} ; 2$.

Hu, Y., S. Rodier, K. Xu, W. Sun, J. Huang, B. Lin, P. Zhai, and D. Josset, 2010: Occurrence, liquid water content, and fraction of supercooled water clouds from combined CALIOP/IIR/MODIS measurements. J. Geophys. Res., 115, D00H34, https://doi.org/ 10.1029/2009JD012384.

Hurrell, J. W., and Coauthors, 2013: The community earth system model: A framework for collaborative research. Bull. Amer. Meteor. Soc., 94, 1339-1360, https://doi.org/10.1175/BAMS-D-12-00121.1.

Iacono, M. J., J. S. Delamere, E. J. Mlawer, M. W. Shephard, S. A. Clough, and W. D. Collins, 2008: Radiative forcing by longlived greenhouse gases: Calculations with the AER radiative transfer models. J. Geophys. Res., 113, D13103, https://doi.org/ 10.1029/2008JD009944.

Igel, A. L., S. C. van den Heever, C. M. Naud, S. M. Saleeby, and D. J. Posselt, 2013: Sensitivity of warm-frontal processes to cloud-nucleating aerosol concentrations. J. Atmos. Sci., 70, 1768-1783, https://doi.org/10.1175/JAS-D-12-0170.1.

Janjić, Z. I., 2002: Nonsingular implementation of the MellorYamada level 2.5 scheme in the NCEP Meso model. NCEP Office Note 437, 61 pp., http://www.emc.ncep.noaa.gov/officenotes/ newernotes/on437.pdf.

Kain, J. S., 2004: The Kain-Fritsch convective parameterization: An update. J. Appl. Meteor., 43, 170-181, https://doi.org/ 10.1175/1520-0450(2004)043<0170:TKCPAU > 2.0.CO;2.

_ _, and J. M. Fritsch, 1990: A one-dimensional entraining/ detraining plume model and its application in convective parameterization. J. Atmos. Sci., 47, 2784-2802, https://doi.org/ 10.1175/1520-0469(1990)047<2784:AODEPM>2.0.CO;2.

- and - 1993: Convective parameterization for mesoscale models: The Kain-Fritsch scheme. The Representation of Cumulus Convection in Numerical Models, Meteor. Monogr., No. 24, Amer. Meteor. Soc., 165-170.

Khairoutdinov, M., and Y. Kogan, 2000: A new cloud physics parameterization in a large-eddy simulation model of marine stratocumulus. Mon. Wea. Rev., 128, 229-243, https:// doi.org/10.1175/1520-0493(2000)128<0229:ANCPPI > 2.0. $\mathrm{CO} ; 2$

Kogan, Y., 2013: A cumulus cloud microphysics parametrization for cloud-resolving models. J. Atmos. Sci., 70, 1423-1436, https://doi.org/10.1175/JAS-D-12-0183.1.

Kooperman, G. J., M. S. Pritchard, S. J. Ghan, M. Wang, R. C. J. Somerville, and L. M. Russell, 2012: Constraining the influence of natural variability to improve estimates of global aerosol indirect effects in a nudged version of the Community Atmosphere Model 5. J. Geophys. Res., 117, D23204, https://doi.org/10.1029/ 2012JD018588.

Kudzotsa, I., V. T. J. Phillips, S. Dobbie, M. Formenton, J. Sun, G. Allen, A. Bansemer, D. Spracklen, and K. Pringle, 2016a: Aerosol indirect effects on glaciated cloud. Part 1: Model description. Quart. J. Roy. Meteor. Soc., 142, 1958-1969, https:// doi.org/10.1002/qj.2791.

$\ldots, \ldots$, and $—, 2016 \mathrm{~b}$ : Aerosol indirect effects on glaciated clouds. Part 2: Sensitivity tests using solute aerosols. Quart. J. Roy. Meteor. Soc., 142, 1970-1981, https://doi.org/10.1002/qj.2790.

Lauer, A., and K. Hamilton, 2013: Simulating clouds with global climate models: A comparison of CMIP5 results with CMIP3 and satellite data. J. Climate, 26, 3823-3845, https://doi.org/ 10.1175/JCLI-D-12-00451.1.

Lim, K.-S. S., J. Fan, L. R. Leung, P.-L. Ma, B. Singh, C. Zhao, Y. Zhang, G. Zhang, and X. Song, 2014: Investigation of aerosol indirect effects using a cumulus microphysics parameterization in a regional climate model.J. Geophys. Res. Atmos., 119, 906-926, https://doi.org/10.1002/2013JD020958.

Liu, X. H., and J. E. Penner, 2005: Ice nucleation parameterization for global models. Meteor. Z., 14, 499-514, https://doi.org/ 10.1127/0941-2948/2005/0059. 
,-- S. J. Ghan, and M. Wang, 2007: Inclusion of ice microphysics in the NCAR Community Atmospheric Model version 3 (CAM3). J. Climate, 20, 4526-4547, https://doi.org/ 10.1175/JCLI4264.1.

Liu, Y., and P. H. Daum, 2004: Parameterization of the autoconversion process. Part I: Analytical formulation of the Kessler-type parameterizations. J. Atmos. Sci., 61, 1539-1548, https://doi.org/10.1175/1520-0469(2004)061<1539:POTAPI> 2.0.CO;2.

Lohmann, U., 2002: A glaciation indirect aerosol effect caused by soot aerosols, Geophys. Res. Lett., 29, 1052, https://doi.org/ 10.1029/2001GL014357.

— view. Atmos. Chem. Phys., 5, 715-735, https://doi.org/10.5194/ acp-5-715-2005.

Ma, P.-L., P. J. Rasch, J. D. Fast, R. C. Easter, W. I. Gustafson, X. Liu, S. J. Ghan, and B. Singh, 2014: Assessing the CAM5 physics suite in the WRF-Chem model: Implementation, resolution sensitivity, and a first evaluation for a regional case study. Geosci. Model Dev., 7, 755-778, https://doi.org/10.5194/ gmd-7-755-2014.

— tion in a global climate model improve the simulation of aerosol-cloud interactions? Geophys. Res. Lett., 42, 5058-5065, https://doi.org/10.1002/2015GL064183.

Mahoney, K. M., 2016: The representation of cumulus convection in high-resolution simulations of the 2013 Colorado Front Range Flood. Mon. Wea. Rev., 144, 4265-4278, https://doi.org/ 10.1175/MWR-D-16-0211.1.

Monin, A. S., and A. M. Obukhov, 1954: Basic laws of turbulent mixing in the surface layer of the atmosphere (in Russian). Tr. Geofiz. Inst., Akad. Nauk SSSR, 24, 163-187.

Morrison, H., and A. Gettelman, 2008: A new two-moment bulk stratiform cloud microphysics scheme in the Community Atmospheric Model (CAM3). Part I: Description and numerical tests. J. Climate, 21, 3642-3659, https://doi.org/10.1175/ 2008JCLI2105.1.

— J. A. Curry, and V. I. Khvorostyanov, 2005: A new doublemoment microphysics parameterization for application in cloud and climate models. Part I: Description. J. Atmos. Sci., 62, 1665-1677, https://doi.org/10.1175/JAS3446.1.

- G. Thompson, and V. Tatarskii, 2009: Impact of cloud microphysics on the development of trailing stratiform precipitation in a simulated squall line: Comparison of one- and two-moment schemes. Mon. Wea. Rev., 137, 991-1007, https:// doi.org/10.1175/2008MWR2556.1.

Otte, T. L., C. G. Nolte, M. J. Otte, and J. H. Bowden, 2012: Does nudging squelch the extremes in regional climate modeling? J. Climate, 25, 7046-7066, https://doi.org/10.1175/JCLI-D-1200048.1.

Partanen, A.-I., and Coauthors, 2014: Global modelling of direct and indirect effects of sea spray aerosol using a source function encapsulating wave state. Atmos. Chem. Phys., 14, 11 731-11 752, https://doi.org/10.5194/acp-14-11731-2014.

Penner, J. E., and Coauthors, 2006: Model intercomparison of indirect aerosol indirect effects. Atmos. Chem. Phys., 6, 3391-3405, https://doi.org/10.5194/acp-6-3391-2006.

Phillips, V. T. J., P. J. DeMott, and C. Andronache, 2008: An empirical parameterization of heterogeneous ice nucleation for multiple chemical species of aerosol. J. Atmos. Sci., 65, 2757-2783, https://doi.org/10.1175/2007JAS2546.1.

Posselt, R., and U. Lohmann, 2009: Sensitivity of the total anthropogenic aerosol effect to the treatment of rain in a global climate model. Geophys. Res. Lett., 36, L02805, https://doi.org/ 10.1029/2008GL035796.

Rosenfeld, D., U. Lohmann, G. B. Raga, C. D. O’Dowd, M. Kulmala, S. Fuzzi, A. Reissell, and M. O. Andreae, 2008: Flood or drought: How do aerosols affect precipitation? Science, 321, 1309-1313, https://doi.org/10.1126/science.1160606.

Skamarock, W. C., and J. B. Klemp, 2008: A time-split nonhydrostatic atmospheric model for weather research and forecasting applications. J. Comput. Phys., 227, 3465-3485, https://doi.org/10.1016/ j.jcp.2007.01.037.

Song, X., and G. J. Zhang, 2011: Microphysics parameterization for convective clouds in a global climate model: Description and single-column model tests. J. Geophys. Res., 116, D02201, https://doi.org/10.1029/2010JD014833

Stauffer, D. R., and N. L. Seaman, 1990: Use of four-dimensional data assimilation in a limited-area model. Part I: experiments with synoptic-scale data. Mon. Wea. Rev., 118, 1250-1277, https://doi.org/10.1175/1520-0493(1990)118<1250:UOFDDA > 2.0.CO;2.

, and $-1994:$ Multiscale four-dimensional data assimilation. J. Appl. Meteor., 33, 416-434, https://doi.org/10.1175/ 1520-0450(1994)033<0416:MFDDA > 2.0.CO;2.

Tao, W.-K., J.-P. Chen, Z. Li, C. Wang, and C. Zhang, 2012: Impact of aerosols on convective clouds and precipitation. Rev. Geophys., 50, RG2001, https://doi.org/10.1029/ 2011RG000369.

Thompson, G., and T. Eidhammer, 2014: A study of aerosol impacts on clouds and precipitation development in a large winter cyclone. J. Atmos. Sci., 71, 3636-3658, https://doi.org/ 10.1175/JAS-D-13-0305.1.

, M. Tewari, K. Ikeda, S. Tessendorf, C. Weeks, J. Otkin, and F. Kong, 2016: Explicitly-coupled cloud physics and radiation parameterizations and subsequent evaluation in WRF highresolution convective forecasts. Atmos. Res., 168, 92-104, https:// doi.org/10.1016/j.atmosres.2015.09.005.

Tonttila, J., H. Jarvinen, and P. Raisanen, 2015: Explicit representation of subgrid cariability in cloud microphysics yields weaker aerosol indirect effect in the ECHAM5-HAM2 climate model. Atmos. Chem. Phys., 15, 703-714, https://doi.org/ 10.5194/acp-15-703-2015.

Twomey, S., 1977: The influence of pollution on the shortwave albedo of clouds. J. Atmos. Sci., 34, 1149-1152, https://doi.org/ 10.1175/1520-0469(1977)034<1149:TIOPOT>2.0.CO;2.

Wang, S.-Y., T.-C. Chen, and S. E. Taylor, 2009: Evaluations of NAM forecasts on midtropospheric perturbationinduced convective storms over the U.S. northern plains. Wea. Forecasting, 24, 1309-1333, https://doi.org/10.1175/ 2009WAF2222185.1.

Wegener, A., 1911: Thermodynamik der Atmosphäre. Leipzig, 331. White, B., E. Gryspeerdt, P. Stier, H. Morrison, G. Thompson, and Z. Kipling, 2017: Uncertainty from the choice of microphysics scheme in convection-permitting models significantly exceeds aerosol effects. Atmos. Chem. Phys., 17, 12 145-12 175, https:// doi.org/10.5194/acp-17-12145-2017.

Xie, X., and X. Liu, 2015: Aerosol-cloud-precipitation interactions in WRF model: Sensitivity to autoconversion parameterization. J. Meteor. Res., 29, 72-81, https://doi.org/10.1007/s13351014-4065-8.

Zelinka, M. D., T. Andrews, P. M. Forster, and K. E. Taylor, 2014: Quantifying components of aerosol-cloud-radiation interactions in climate models. J. Geophys. Res. Atmos., 119, 7599-7615, https://doi.org/10.1002/2014JD021710. 
Zhang, G. J., and N. A. McFarlane, 1995: Sensitivity of climate simulations to the parameterization of cumulus convection in the Canadian Climate Centre General Circulation Model. Atmos.-Ocean, 33, 407-446, https://doi.org/10.1080/ 07055900.1995.9649539.

Zhang, Y., P. Karamchandani, T. Glotfelty, D. G. Streets, G. Grell, A. Nenes, F. Yu, and R. Bennartz, 2012: Development and initial application of the global-through-urban weather research and forecasting model with chemistry (GU-WRF/Chem). J. Geophys. Res., 117, D20206, https://doi.org/10.1029/ 2012JD017966.

Zheng, Y., K. Alapaty, J. S. Herwehe, A. Del Genio, and D. Niyogi, 2016: Improving high-resolution weather forecasts using the Weather Research and Forecasting (WRF) Model with an updated Kain-Fritsch scheme. Mon. Wea. Rev., 144, 833-860, https://doi.org/10.1175/MWR-D-15-0005.1. 